NBER WORKING PAPER SERIES

NON-PARAMETRIC TESTS OF THE TRAGEDY OF THE COMMONS

\author{
H. Spencer Banzhaf \\ Yaqin Liu \\ Martin Smith \\ Frank Asche \\ Working Paper 26398 \\ http://www.nber.org/papers/w26398 \\ NATIONAL BUREAU OF ECONOMIC RESEARCH \\ 1050 Massachusetts Avenue \\ Cambridge, MA 02138 \\ October 2019, Revised January 2021
}

We thank Anna Birkenbach, Rahul Deb, James Fenske, Matt Kotchen, Dean Lueck, Chuck Mason, Kurt Schnier, Jeff Wooldridge and participants at Camp Resources XX, the 2018 Southern Economic Association conference, the 2018 World Congress of Environmental and Resource Economists, the 2019 AERE Conference, and seminars at the College of Charleston, Georgetown University, University of British Columbia, and the University of Indiana for helpful comments and discussions. Liu and Smith thank the Knobloch Family Foundation for financial support of this research. The views expressed herein are those of the authors and do not necessarily reflect the views of the National Bureau of Economic Research.

At least one co-author has disclosed additional relationships of potential relevance for this research. Further information is available online at http://www.nber.org/papers/w26398.ack

NBER working papers are circulated for discussion and comment purposes. They have not been peer-reviewed or been subject to the review by the NBER Board of Directors that accompanies official NBER publications.

(C) 2019 by H. Spencer Banzhaf, Yaqin Liu, Martin Smith, and Frank Asche. All rights reserved. Short sections of text, not to exceed two paragraphs, may be quoted without explicit permission provided that full credit, including $\odot$ notice, is given to the source. 
Non-Parametric Tests of the Tragedy of the Commons

H. Spencer Banzhaf, Yaqin Liu, Martin Smith, and Frank Asche

NBER Working Paper No. 26398

October 2019, Revised January 2021

JEL No. C14,C72,D21,D23,Q2,Q3

\begin{abstract}
The "tragedy of the commons" occurs when agents over-exploit a common resource. Although often applied, the canonical behavioral model of the tragedy has rarely been tested directly. We derive a non-parametric test of behavior consistent with the tragedy-of-the-commons model. Our approach allows for an arbitrarily concave, differentiable production function of total inputs and for heterogeneous agents with arbitrarily convex, differentiable costs of supplying inputs. We develop three additional tests to allow for sampling error, to establish metrics defining distance from the data to the model, and to account for measurement error in the data. Applying our approach to panel data of Norwegian commercial fishers, we find evidence rejecting the tragedyof-the-commons model. Significantly, we find rejection rates of the model increase after property rights reforms limited access to the resource for a segment of the fleet. Results from parametric difference-in-difference regressions are consistent with these findings.
\end{abstract}

\author{
H. Spencer Banzhaf \\ Martin Smith \\ Department of Economics \\ Nicholas School \\ Andrew Young School of Policy Studies \\ Georgia State University \\ Duke University \\ Box 90328 \\ P.O. Box 3992 \\ Durham, NC 27708 \\ Atlanta, GA 30302 \\ marsmith@duke.edu \\ and NBER \\ hsbanzhaf@gsu.edu \\ Frank Asche \\ Yaqin Liu \\ University of Florida \\ Nicolas School of the Environment \\ frank.asche@ufl.edu \\ Duke University \\ Durham, NC 27708 \\ yliu64@student.gsu.edu
}




\title{
Non-Parametric Tests of the Tragedy of the Commons
}

\author{
Spencer Banzhaf, Yaqin Liu, Martin D. Smith, and Frank Asche
}

\section{Introduction}

The "tragedy of the commons" occurs when strategic incentives, unchecked by property rights or other institutional arrangements, undermine the potential value of a commonly held resource. Because individuals do not bear the full cost when they utilize the common resource, they have an incentive to use it too intensively, relative to the group's welfare. In the standard model, individuals receive a prorated share of collective output, proportionate to their inputs, so by increasing inputs they can obtain a larger share of the pie (Gordon 1954, Weitzman 1974, Dasgupta and Heal 1979). Classic examples include sending cattle to a common pasture (Huffaker and Wilen 1991), cooperative firms (Sen 1966), extracting oil from a common pool (Libecap and Wiggins 1984, Baltrop and Schnier 2016), extracting groundwater (Brazović et al. 2010, Burlig et al. 2020, Ayres et al. 2019), and fishing from the sea (Gordon 1954, Huang and Smith 2014). Stavins (2011) provides a review.

Like the prisoner's dilemma, the tragedy of the commons represents a behavioral dilemma highlighting the tension between individual and group rationality. Potentially, groups can avoid the trap of open access by devising ways to cooperate and limit access to the commons, effectively managing common-pool resources (Ciriacy-Wantrup and Bishop 1975, Ostrom 1990). Evidence from laboratory experiments suggests that when individuals make decisions anonymously and without communication, they over-exploit common-pool resources, producing the "tragedy." But when individuals can communicate or build other institutions to change incentives, they can overcome the tragedy (Dietz et al. 2003, Ostrom 2009). Unfortunately, many (perhaps most) major common-pool resources do not fit Ostrom's vision of effective self-governance. Accordingly, modeling agents' behavior under open-access conditions will continue to be critically important.

Surprisingly, then, there have been few empirical tests of the standard model with naturally occurring data. Many studies have considered the aggregate effects of different property rights regimes. For example, Kirkley et al. (2002) and Felthoven et al. (2009) outline approaches for measuring excess capacity in an industry exploiting a common-pool resource, with resources 
"wasted" on capital in the race to exploit. This approach requires estimating a production function for firms. Others consider the effects of establishing property rights on resource stocks and the race to exploit. Balthrop and Schnier (2016) find that unitization of oil and gas reserves decreases the race to pump. In fisheries, Birkenbach et al. (2017) and Costello and Grainger (2018) find that individual catch shares can slow the race to fish and reduce over-exploitation of fisheries. These policy-relevant outcomes are consistent with models of open access and the prescribed remedy of property rights, but they do not actually test individual behavior.

Highlighting open access as a behavioral dilemma, Huang and Smith (2014) conducted the first micro-level empirical investigation of strategic behavior in a common pool. Using strong function form assumptions, they develop a dynamic structural model of the microeconomic behavior of fishers operating in an open-access fishery. Each fisher chooses effort to maximize expected utility given all other fishers' actions. With estimates from their model, one can quantify the potential efficiency gains of property rights reforms. However, their approach presupposes Nash behavior in a commons game as a maintained assumption. Testing the validity of such models under minimal assumptions remains an unexplored area.

In this paper, we introduce a non-parametric revealed preference test for the canonical behavioral model of the tragedy of the commons. Our test has the advantage of requiring no assumptions about production functions or cost functions (beyond convexity). The test is derived from the key characteristics of the tragedy of the commons that each agent maximizes its objective function independently and from a proportionate sharing rule. It builds on results from Carvajal et al. (2013), who developed a similar revealed preference test for Cournot equilibrium, deriving properties that hold when firms are strategically interacting as predicted by that model. But just as Cournot competition dissipates monopoly rents, open-access competition dissipates resource rents. Accordingly, using their logic, we can derive similar properties that hold under the strategic interactions of the tragedy-of-the-commons (TOC) model. The test can be implemented with panel data of individual inputs and total output. In particular, given panel data on each agent's input and the total output from exploitation, we show that a data set is consistent with the tragedy of the commons with convex cost functions if and only if there is a solution to a linear program that we can explicitly construct from the data. Accordingly, the tests we derive can be applied to various settings with common-pool resource extraction such as fisheries, oil and gas, minerals, groundwater, grazing on common lands, and deforestation. 
Further extending the logic of Carvajal et al., we derive additional tests that incorporate sampling and/or measurement errors in total input and output. Sampling error is modeled as a latent parameter, which can be inferred from our linear program under the null hypothesis of behavior consistent with the tragedy of the commons. The model allows the analyst to impose boundaries on permissible sampling errors based on credible information or assumptions. Sampling errors change the testable properties, increasing the domain of the linear program, which make the test less stringent. Hence, compared to the basic tests, tests with sampling errors reduce rejection rates of the model.

We also derive new tests to gauge the minimum distance of the set of recovered marginal costs from those that are consistent with the model. Building on ideas first proposed by Afriat (1972), Diewert (1973), and Varian (1985), we include an adjustment factor in the model to guarantee that data would always pass the behavioral test. We apply a nonlinear program to reveal the minimal magnitude of the adjustments required, which can be interpreted as a quantitative measure of distance from the model. In one version of this approach, we consider behavioral errors in which the marginal costs used in the firms' objective functions depart from the true costs. In another version, we consider measurement error in inputs. Using these errors, we apply a KolmogorovSmirnov test to inform probability distributions for rejections of the model. These extensions are of independent interest, as they also could be applied to tests of the Cournot model (as in Carvajal et al.) as well as the tragedy of the commons. Using simulated data generated from known behavioral patterns, we confirm that these tests and metrics can detect departures from the TOC model.

We apply our tests empirically to the Norwegian coastal fishery for cod and other whitefish (the largest fishery in Norway and a major contributor to the global market for whitefish). Before 2003, this fishery was relatively open access, but in 2003 individual property rights were introduced for large, but not small, vessels, suggesting a difference-in-differences research design. Using our test, the TOC model is rejected to a greater degree after these reforms for large vessels. This pattern highlights the intuitiveness of the test and its relevance to policy questions. Results from the test show how changing property rights (and thus incentives) can change behavior in the commons. Interestingly, they also suggest that even as the reforms moved large vessels away from TOC-like behavior, they may have increased it for small vessels. Supplemental analyses support this interpretation. This finding is consistent with theoretical intuition but has not previously been shown using real-world behavioral data and without imposing strong parametric assumptions. 
The paper is organized as follows. Section 2 derives the theoretical results for the classic model of the average return game in which agents select their inputs and each unit of input receives the average return (rather than marginal return). Section 3 offers additional extensions to the model, including quantifying distance to the model, conducting statistical tests, and incorporating measurement error. Section 4 discusses the empirical application, and Section 5 presents the results. Section 6 concludes.

\section{Principle Result: A Nonparametric Test of the Tragedy of the Commons}

\subsection{The Average Return Game}

Consider an industry consisting of $I$ profit-maximizing firms, indexed by $i=1,2, \ldots, I$, each having free access to an exogenously fixed common-pool resource. There are $T$ decision periods indexed by $t=1,2, \ldots, T$. Denote $q_{i, t}$ as the extraction effort by firm $i$ in period $t$. For example, $q_{i, t}$ might be the number of fishing vessel-days in year $t$. Let $Q_{t}=\sum_{i} q_{i, t}$ be the total level of effort applied to the resource at time $t$. The differentiable production function for the industry at time $t$ is $Y_{t}=F_{t}\left(Q_{t}\right)$, with $F(0)=0, F^{\prime}(Q)>0$, and $F^{\prime}$ non-increasing for all $t$.

Following the canonical commons model (Gordon 1954, Weitzman 1974, Dasgupta and Heal 1979, Cornes and Sandler 1996), each firm's extraction is proportionate to its share of input. Thus, firm $i^{\prime}$ s revenue in period $t$ is $\frac{q_{i, t}}{Q_{t}} * p_{t} F_{t}\left(Q_{t}\right)$, where $p_{t}$ denotes the market price of output (e.g. fish) at time $t$. This assumption captures the characteristic of open-access resources that factors tend to receive their average rather than their marginal product. Finally, let $C_{i}\left(q_{i, t}\right)$ denote firm $i$ 's cost function, which is a differentiable and non-decreasing function of $q$.

We say a panel data set $\mathcal{O}=\left\{p_{t} F_{t},\left(q_{i, t}\right)_{i \in 1 \ldots N}\right\}_{t \in 1 \ldots T}$ is consistent with the tragedy of the commons if there exist cost functions $\bar{C}_{i}$ for each firm $i$, and concave production functions $\bar{F}_{t}$ for each observation $t$ that jointly satisfy the following two conditions:

(i) $\bar{F}_{t}\left(Q_{t}\right)=F_{t}$

(ii) $q_{i, t} \in \operatorname{argmax}_{\tilde{q}_{i, t} \geq 0}\left\{\frac{\tilde{q}_{i, t}}{Q_{t}} * p_{t} F_{t}\left(Q_{t}\right)-\bar{C}_{i}\left(\tilde{q}_{i, t}\right)\right\}$.

Condition (i) says the production function must be consistent with observed output at time $t$. Condition (ii) says firm $i$ 's input at time $t$ maximizes its profit given the inputs of all other firms (a 
standard Nash assumption).

Note that we do not need to estimate the production function. We allow the analysis to explain the data using any arbitrary concave production function, as long as it passes through the observed total output and inputs, $p_{t} F_{t}\left(Q_{t}\right)$ and $Q_{t}$, at each decision period. Similarly, no restrictions are placed on firms' cost functions except that they are increasing and convex.

To see how we can avoid functional form assumptions, consider firm i's profit-maximization problem at time $t$ :

$$
\max _{q_{i, t}} \frac{q_{i, t}}{Q_{t}} * p_{t} F_{t}\left(Q_{t}\right)-C_{i}\left(q_{i, t}\right)
$$

Taking other firms' actions as given, the first-order condition is:

$$
\frac{q_{i, t}}{Q_{t}} * p_{t} F_{t}^{\prime}\left(Q_{t}\right)+\left(1-\frac{q_{i, t}}{Q_{t}}\right) * \frac{p_{t} F_{t}\left(Q_{t}\right)}{Q_{t}}=C_{i, t}^{\prime}
$$

This is the standard result that firms equate marginal cost to a weighted average of marginal returns and average returns (Weitzman 1974, Dasgupta and Heal 1979). In the case of a monopolist, $q_{i, t}=$ $Q_{t}$ and the entire weight is on the efficient condition to equate marginal cost to marginal return. In the limit, as the firms grows small, $q_{i, t} / Q_{t}$ goes to zero and the firms equate marginal cost to average revenue, thus depleting all resource rents (as in Gordon 1954).

Rearranging terms, we obtain:

$$
\frac{p_{t} F_{t}\left(Q_{t}\right)-Q_{t} C_{i, t}^{\prime}}{q_{i, t}}=\frac{p_{t} F_{t}\left(Q_{t}\right)}{Q_{t}}-p_{t} F_{t}^{\prime}\left(Q_{t}\right)
$$

Notice in Equation (3) that the left-hand side involves firm-specific terms (inputs $q_{i, t}$ and marginal costs $C_{i, t}^{\prime}$ ) while the right-hand side involves only market-wide data (total revenue $p_{t} F_{t}\left(Q_{t}\right)$, marginal revenue product $p_{t} F_{t}^{\prime}$, and total input $Q_{t}$ ). Consequently, from the first-order condition, we obtain a common ratio property analogous to Carvajal et al.'s Cournot model:

(4) $\frac{p_{t} \mathrm{~F}_{t}\left(Q_{t}\right)-Q_{t} C_{i, t}^{\prime}}{q_{i, t}}=\frac{p_{t} \mathrm{~F}_{t}\left(Q_{t}\right)-Q_{t} C_{j, t}^{\prime}}{q_{j, t}}=\cdots=\frac{p_{t} \mathrm{~F}_{t}\left(Q_{t}\right)-Q_{t} C_{I, t}^{\prime}}{q_{I, t}} \geq 0 \forall t \in T$.

In other words, in each period, functions of the total extraction effort and firm-specific marginal costs should all be equal. The expressions are nonnegative given the concavity of the production function. 
Moreover, because each firm's cost function is convex, the array $\left\{C_{i, t}^{\prime}\right\}$ displays increasing marginal costs for each firm $i$. Thus, if the cost function is time-invariant, we also have the comonotone property, such that for all $i$,

$$
q_{i, t}>q_{i, t^{\prime}} \rightarrow C_{i, t}^{\prime} \geq C_{i, t^{\prime}}^{\prime}
$$

Consequently, a set of observations is consistent with the tragedy of the commons with convex cost functions if and only if there exist nonnegative numbers $\left\{C_{i, t}^{\prime}\right\}$ for all $i, t$ that obey the common ratio and co-monotone properties.

In the following example, we show that certain data sets are inconsistent with the tragedy of the commons given the interplay of the two properties. Consider the following observations of two firms $i$ and $j$ sharing a common-pool resource:

(i) At observation $t, p_{t} F_{t}\left(Q_{t}\right)=50, q_{i, t}=50, q_{j, t}=100$.

(ii) At observation $t^{\prime}, p_{t^{\prime}} F_{t^{\prime}}\left(Q_{t^{\prime}}\right)=350, q_{i, t^{\prime}}=70, q_{j, t^{\prime}}=60$.

Re-arranging the common-ratio property at $t^{\prime}$ to isolate $C_{j, t^{\prime}}^{\prime}$ and using the fact that $\frac{q_{j, t^{\prime}}}{q_{i, t^{\prime}}} C_{i, t^{\prime}}^{\prime} \geq 0$, we have:

$C_{j, t^{\prime}}^{\prime}=\frac{p_{t^{\prime}} F_{t^{\prime}}\left(Q_{t^{\prime}}\right)}{Q_{t^{\prime}}}-\frac{q_{j, t^{\prime}}}{q_{i, t^{\prime}}} \frac{p_{t^{\prime}} F_{t^{\prime}}\left(Q_{t^{\prime}}\right)}{Q_{t^{\prime}}}+\frac{q_{j, t^{\prime}}}{q_{i, t^{\prime}}} C_{i, t^{\prime}}^{\prime} \geq \frac{p_{t^{\prime}} F_{t^{\prime}}\left(Q_{t^{\prime}}\right)}{Q_{t^{\prime}}}-\frac{q_{j, t^{\prime}}}{q_{i, t^{\prime}}} \frac{p_{t^{\prime}} F_{t^{\prime}}\left(Q_{t^{\prime}}\right)}{Q_{t^{\prime}}}=0.385$.

Now, we know from the first-order condition (2) that $C_{i, t}^{\prime}<\frac{p_{t} F_{t}\left(Q_{t}\right)}{Q_{t}}$, at each time $t$ for all $i$, because $C_{i, t}^{\prime}=\frac{q_{i, t}}{Q_{t}}\left(p_{t} F_{t}^{\prime}\left(Q_{t}\right)-\frac{p_{t} F_{t}\left(Q_{t}\right)}{Q_{t}}\right)+\frac{p_{t} F_{t}\left(Q_{t}\right)}{Q_{t}}$ and $F_{t}^{\prime}\left(Q_{t}\right)-\frac{F_{t}\left(Q_{t}\right)}{Q_{t}}<0$ given the concavity of production function. Thus, $C_{j, t}^{\prime}<\frac{p_{t} F_{t}\left(Q_{t}\right)}{Q_{t}}=0.33$. In addition, from the co-monotone property, we have $C_{j, t^{\prime}}^{\prime} \leq C_{j, t}^{\prime}$ because $q_{j, t^{\prime}}<q_{j, t}$. Thus, in sum, $0.385 \leq C_{j, t^{\prime}}^{\prime}<C_{j, t}^{\prime}<0.33$, which is clearly a contradiction. Thus, there are no nonnegative marginal costs that satisfy the common-ratio property and the co-monotone properties. The data in Example 1 are inconsistent with the TOC model.

\subsection{Implementation: A Linear Program for the Test}

Our approach to testing the TOC model can be reformulated as a simple linear program. Given panel data on each agent's input and the total output from exploitation, we find nonnegative marginal costs, $\left\{C_{i, t}^{\prime}\right\}$, for all agents $i$ at each time $t$, which satisfy the common-ratio property (4) and 
the co-monotone property (5). This linear program is analogous to the conditions specified in Afriat's Theorem for testing whether consumers' choices are consistent with utility-maximizing behavior or, equivalently, the Generalized Axiom of Revealed Preference (GARP) (Afriat 1967). This overall approach encompasses a diversity of research programs and has been extended to a wide array of settings (Chambers and Echenique 2016, Hands 2014), including firms' costs (Varian 1984) and Cournot competition (Carvajal et al. 2013).

In our context, a set of observations is consistent with the tragedy of the commons with convex cost functions if and only if, given the observed $p_{t} \mathrm{~F}_{t}, q_{i, t}$, and $Q_{t}$ there are numbers $C_{i, t}^{\prime}$ satisfying:

(i) $\frac{p_{t} \mathrm{~F}_{t}\left(Q_{t}\right)-Q_{t} C_{i, t}^{\prime}}{q_{i, t}}=\frac{p_{t} \mathrm{~F}_{t}\left(Q_{t}\right)-Q_{t} C_{j, t}^{\prime}}{q_{j, t}} \geq 0 \forall i, j \in I, \forall t \in T$;

(ii) $\left(q_{i, t}-q_{i, t^{\prime}}\right)\left(C_{i, t}^{\prime}-C_{i, t^{\prime}}^{\prime}\right) \geq 0 \forall i \in I, \forall t, t^{\prime} \in T$;

(iii) $C_{i, t}^{\prime} \geq 0 \forall i \in I, \forall t \in T$.

See Appendix A for a proof.

Condition (i) is the common-ratio property which follows from the first-order condition; condition (ii) is the co-monotone property which follows from the convexity of the cost function; and condition (iii) is a non-negativity constraint which follows from the fact that the cost function is increasing. For a panel data set, failure to obtain a solution to any element in the marginal cost set $\left\{C_{i, t}^{\prime}\right\}_{\forall i \in I, \forall t \in T}$, will result in a rejection of the model.

To understand the implications of this test, we emphasize three features. First, the test rejects or fails to reject an entire data set, not individual observations or individual firms. In this respect, it is similar to tests of consumers' choices, in which entire data sets are or are not consistent with GARP, not individual choices. However, one can always throw out particular observations from the data set and consider the effect of doing so. Thus, taking random subsets of the data, one can generate rejection rates, as a quantitative measure of "how much" the data are inconsistent with the TOC model. Further, one can isolate data from particular firms or periods to see if the data set is more likely to be rejected with or without them. Below, we leverage this possibility in our empirical applications to test the effect on rejection rates of including data generated under differing property rights regimes. 
Second, our approach tests the minimum necessary conditions for the above behavioral model. Under the model's behavioral assumptions, the test eliminates any type I error. On the other hand, it is weak in the sense of potentially allowing a great deal of type II error. That is, rejection of the model gives one confidence that the data indeed are not consistent with the TOC model, but - as always - failure to reject does not guarantee the model is true (nor, of course, that alternative models are false). This is not a limitation of our approach so much as a limitation of what can be said about the behavioral model: If further restrictions would lead to more rejections, then arguably it is the auxiliary hypotheses that are being rejected, not the fundamentals of the behavioral model. It is always the case that failure to reject a null hypothesis does not guarantee it to be true.

Third, even with the very weak assumptions we bring to the model, we can learn a great deal from the tests we derive from it. Data sets that are consistent with the TOC model are inconsistent with at least some rival models. Consider, for example, the case of non-tradable quotas, which restrict each firm to extract only up to its quota. Although non-tradability prevents cost minimization subject to total extraction by the group (as firms with high costs at the margin may be allocated quota that cannot be traded to low-cost firms), non-tradable quotas do have some advantages. Typically, they cap the total allowable extraction so as to protect the sustainability of a resource. Additionally, because a firm's share is exogenous to how quickly it extracts, individual quotas can prevent a "race" within the time period over which the quota is defined in order to get a larger share of the group quota. By contrast, group-wide quotas, which also protect the sustainability of the resource, actually incentivize racing to extract (Homans and Wilen 1997).

Importantly, non-tradable quotas do not lead to a common ratio property like Equation (4). To see this, note that the objective function would now be written as a constrained optimization problem:

$$
\max _{q_{i, t}} \frac{q_{i, t}}{Q_{t}} * p_{t} F_{t}\left(Q_{t}\right)-C_{i}\left(q_{i, t}\right)+\lambda_{i, t}\left(L_{i, t}-\frac{q_{i, t}}{Q_{t}} * F_{t}\left(Q_{t}\right)\right),
$$

where $L_{i, t}$ is the quota limit and $\lambda_{i, t}$ is the shadow cost of that limit. Note output prices appear in the revenue term but not the constraint. The revised first-order condition is: 


$$
\left(p_{t}-\lambda_{i, t}\right)\left[\frac{q_{i, t}}{Q_{t}} * F_{t}^{\prime}\left(Q_{t}\right)+\left(1-\frac{q_{i, t}}{Q_{t}}\right) * \frac{F_{t}\left(Q_{t}\right)}{Q_{t}}\right]=C_{i, t}^{\prime}
$$

The quota is associated with a firm-specific shadow price on extraction, so it is equivalent to the original problem with an adjusted output price. Finally, rearranging terms, we obtain:

$$
\frac{F_{t}\left(Q_{t}\right)-Q_{t} C_{i, t}^{\prime} /\left(p_{t}-\lambda_{i, t}\right)}{q_{i, t}}=\frac{F_{t}\left(Q_{t}\right)}{Q_{t}}-F_{t}^{\prime}\left(Q_{t}\right)
$$

Taking this equation in isolation, it might appear that instead of solving the linear program by finding numbers $C_{i, t}^{\prime}$, we could instead simply solve for numbers $C_{i, t}^{\prime} /\left(p_{t}-\lambda_{i, t}\right)$. However, the latter numbers would not be expected to satisfy the co-monotone property, which is based on the convexity of $C_{i, t}^{\prime}$ alone. For example, ceteris paribus, higher effort one year might come with a higher quota, but this would tend to lower $\lambda_{i, t}$ (as the quota is less binding), and hence decrease the expression $C_{i, t}^{\prime} /\left(p_{t}-\lambda_{i, t}\right)$, perhaps violating the co-monotone property.

Thus, we would expect a non-tradeable individual quota regime to lead to higher rejection rates. We leverage this insight in our empirical work below.

\section{Extensions}

In this section, we extend the model in various ways. Our extensions can be applied to other settings as well, including the case of Cournot competition considered by Carvajal et al. (2013). Thus, they represent an additional contribution of this research.

\subsection{The Test with Sampling Error}

The test we derived in Section 2 assumes that data are observed without error. Moreover, it assumes data from a census (not just sample) of users, so that $Q=\sum_{i} q_{i}$ and total catch $F(Q)$ are observed. In this section, we consider the case where only a sample of users are observed, so that total effort $Q$ and total revenue $F$ are estimates based on a sample mean times $N$. With sampling, even if the sample of individual effort and revenue is measured without error, total effort and total revenue are observed with error because they are based on the sample averages. Let $\alpha_{t}$ and $\beta_{t}$ be the respective proportionate errors in the sample averages, so we observe $p_{t} \widehat{F}_{t}=p_{t} F_{t} * \alpha_{t}$ and $\hat{Q}_{t}=Q_{t} * \beta_{t}$, for $\alpha_{t}>0$ and $\beta_{t}>0$ (i.e., we observe some revenue and some input). Then the 
common ratio property becomes $\frac{\alpha_{t} p_{t} \mathrm{~F}_{t}\left(Q_{t}\right)-\beta_{t} Q_{t}\left(C_{i, t}^{\prime}\right)}{q_{i, t}}=\frac{\alpha_{t} p_{t} \mathrm{~F}_{t}\left(Q_{t}\right)-\beta_{t} Q_{t}\left(C_{j, t}^{\prime}\right)}{q_{j, t}}$. Dividing both sides by $\beta_{t}$ and letting $\gamma_{t}=\alpha_{t} / \beta_{t}$, we can write the linear program with sampling errors as:

(i) $\frac{\gamma_{t} p_{t} \mathrm{~F}_{t}\left(Q_{t}\right)-Q_{t}\left(C_{i, t}^{\prime}\right)}{q_{i, t}}=\frac{\gamma_{t} p_{t} \mathrm{~F}_{t}\left(Q_{t}\right)-Q_{t}\left(C_{j, t}^{\prime}\right)}{q_{j, t}} \geq 0, \forall i, j \in I, \forall t \in T$;

(ii) $\left(q_{i, t}-q_{i, t^{\prime}}\right)\left(C_{i, t}^{\prime}-C_{i, t^{\prime}}^{\prime}\right) \geq 0, \forall i \in I, \forall t, t^{\prime} \in T$;

(iii) $C_{i, t}^{\prime} \geq 0, \forall i \in I, \forall t \in T$,

(iv) $\gamma_{t}>0, \forall t \in T$.

This test is still based on the micro data for the observed sample, but it allows for an adjustment in the aggregate data to account for sampling error.

Without sampling errors, we would look for marginal costs that satisfy properties above without $\gamma_{t}$. We treat $\gamma_{t}$ as unknown and let the linear program look for the set of $\left\{\gamma_{t}, C_{i, t}^{\prime}\right\}_{\forall i \in I, \forall t \in T}$ that rationalizes the data with the model. The idea is to ask if there are plausible sampling errors in the estimated aggregate $\hat{Q}_{t}$ and $p_{t} \hat{F}_{t}$ that would make the micro data consistent with the model. Furthermore, when more information (or modeler-defined judgement) of direction or range of the sampling errors is available, we can easily add bounds on the sampling errors to the constraints. ${ }^{1}$ Compared to the basic model, we would expect lower rejection rates of the model when sampling error is allowed.

\subsection{Distance to the Model and Statistical Tests}

Building on the marginal-cost-consistency methods described in Afriat (1972), Diewert (1973), and Varian (1985), we can gauge the distance of the revealed marginal costs in our tests to those that are consistent with the TOC model. Similar to Varian's approach of finding a minimal perturbation of the budget constraints that would make observed choices consistent with GARP, we can find a minimal adjustment to marginal costs needed to turn a rejection of the model to an acceptance. The minimal adjustment represents the distance of observed behavior to the behavior characterized by the model.

We implement this method by adding adjustment factors to marginal costs in the common

\footnotetext{
${ }^{1}$ For example, if the modeler suspects $\beta>1$, concavity of $F$ implies $\alpha<\beta$, so $\gamma<1$; the opposite would follow if $\beta<1$.
} 
ratio property, but not the co-monotone property. The idea is that the marginal costs in the comonotone property describe the true convexity of the cost function, but firms may treat the marginal costs as being different in their objective function. Mathematically, by adding adjustment factors to the common-ratio property, we relax the constraints enforced by maximizing behavior but leave the co-monotone property intact to maintain the constraints of convex costs. In this way, we can always find marginal costs together with adjustments to make the observed data consistent with the model. We use a linear program to find the minimal magnitude of the adjustment, which is the minimized distance from the revealed marginal costs to those that would be consistent with the model. We denote them as revealed marginal costs and model-consistent marginal costs below, respectively. Based on these solutions, we then derive Kolmogorov-Smirnov and chi-squared tests to inform statistical rejection of the model.

We use the following quadratic program:

$$
\min _{C_{i, t}^{\prime}, \delta_{i, t}} \sum_{t} \sum_{i} \delta_{i, t}^{2}
$$

Subject to:

(i) $\frac{p_{t} \mathrm{~F}_{t}\left(Q_{t}\right)-Q_{t}\left(C_{i, t}^{\prime}+\delta_{i, t}\right)}{q_{i, t}}=\frac{p_{t} \mathrm{~F}_{t}\left(Q_{t}\right)-Q_{t}\left(C_{j, t}^{\prime}+\delta_{j, t}\right)}{q_{j, t}} \geq 0, \forall i, j \in I, \forall t \in T$;

(ii) $\left(q_{i, t}-q_{i, t^{\prime}}\right)\left(C_{i, t}^{\prime}-C_{i, t^{\prime}}^{\prime}\right) \geq 0 \forall i \in I, \forall t, t^{\prime} \in T$;

(iii) $C_{i, t}^{\prime} \geq 0 \forall i \in I, \forall t \in T$.

$\delta_{i, t}$ is the minimum adjustment factor on marginal cost $C_{i, t}^{\prime}$. Note that the $\delta_{i, t}$ appear only in condition (i), not (ii). Again, the intuition here is that the cost functions are convex (ii), but firms may make errors in their optimization that show up in their first-order conditions (i). By construction, solutions $\left\{\delta_{i, t}, C_{i, t}^{\prime}\right\}$ satisfying (i)-(iii) always exist. ${ }^{2}$ Hence, we can identify and quantify the minimal squared adjustment factors $\left\{\delta_{i, t}\right\}$, which are the minimal distances between the revealed marginal costs to the model-consistent marginal costs.

\footnotetext{
${ }^{2}$ The adjustment factors expand the domain of marginal costs to the reals. As they do not have to satisfy the co-monotone constraint, adjustment factors can always be found to satisfy the common-ratio property. Note that it would not do to incorporate the adjustment into all equations, which would be identical to the original model. If there are no numbers $C^{\prime}{ }_{i, t}$ satisfying (i)-(iii), there are no numbers $\left(C^{\prime}{ }_{i, t}+\delta_{i, t}\right)$ either.
} 


\section{Statistical Tests}

Taking the minimal distance found above, we can conduct a Kolmogorov-Smirnov (KS) test of the null hypothesis that the data are consistent with the model. Denote the set of marginal costs that are consistent with the model as $\left.\widetilde{\left\{m c_{l, t}\right.}\right\}_{i \in I, \forall t \in T}$ (model-consistent marginal costs). The model-consistent marginal costs can be obtained from the quadratic program in this section as $C_{i, t}^{\prime}+\delta_{i, t}$. Denote the revealed marginal costs of an observed data set as $\left\{\widehat{m c_{l, t}}\right\}_{i \in I, \forall t \in T \text {. The }}$ revealed marginal costs are obtained in the quadratic program as $C_{i, t}^{\prime}$.

The two-sample KS test directly compares the distance between the cumulative distribution function (CDF) of two sample variables and checks if the two samples are from the same distribution. The empirical distance function is specified as $D_{n, m}=\sup _{x}\left|F_{1, n}(x)-F_{2, m}(x)\right|$, which represents the supremum of the distance between the CDF of sample 1 with $n$ observations and the CDF of sample 2 with $m$ observations. In our case, sample 1 consists of the model-consistent marginal costs, and sample 2 the revealed marginal costs. The sample size for both samples is $I *$ T. $D_{n, m}$ is a vector consisting of the distance between the two CDFs at each value of the sample variable represented by $x$, which in our case is the marginal cost. We can take small intervals on the domain of marginal costs, obtain values of the two CDFs, and find the maximum distance of the two CDFs. The null hypothesis is rejected at level $\alpha$ if the maximum distance is larger than the critical value, that is $D_{n, m}>c(\alpha) * \sqrt{\frac{m+n}{m * n}}$, at critical level $\alpha$.

Alternatively, we can assume the model-consistent marginal costs follow a log-normal distribution $N\left(\mu, \sigma^{2}\right)$ with the lower limit zero. Under the null hypothesis that an observed data set is consistent with the model, revealed MCs would converge to the distribution of model-consistent MCs in the limit. Hence, $z_{i, t}=\frac{\log \left(\widehat{m c_{l, t}}\right)-\log \left(\widetilde{m c_{l, t}}\right)}{\sigma}$ follows a standard normal distribution. Moreover, we can easily obtain $z_{i, t}$ from the program, given that $\widehat{m c_{l, t}}=C_{i, t}^{\prime}$ and $\widetilde{m c_{l, t}}=C_{i, t}^{\prime}+\delta_{i, t}$. As a result, $S=\sum_{t=1}^{T} \sum_{i=1}^{I} z_{i, t}^{2}$ follows a chi-squared distribution with $T * I$ degrees of freedom. With a large sample, we can substitute the sample variance for the population variance. When $S$ is larger than the critical value of a chi-squared distribution, we can reject the null that the data are consistent with the TOC model statistically. 


\subsection{Measurement Error in $q$}

In Section 3.2, we considered distance to the model in the space of marginal costs as they show up in Condition (i), marginal cost consistency. An alternative is to consider distance to the model in the space of inputs $q_{i, t}$. If we allow those to be measured with error, then we can frame this approach as asking, how large would measurement error in inputs have to be for it to explain any rejections of the model?

In this case, we can again minimize $\sum_{t} \sum_{i} \delta_{i, t}^{2}$, but with $q_{i, t}$ replaced by $\left(q_{i, t}+\delta_{i, t}\right)$ and similarly $Q_{t}$ replaced by $\left(Q_{t}+\sum_{i} \delta_{i, t}\right)$ everywhere in the model. If we denote the model-consistent inputs as $\tilde{q}_{i, t}=\left(q_{i, t}+\delta_{i, t}\right)$ and similarly the sum $\tilde{Q}_{t}=\left(Q_{t}+\sum_{i} \delta_{i, t}\right)$, we can write this more succinctly as finding the model-consistent inputs $\tilde{q}_{i, t}$ that are closest to the observed inputs. This involves the non-linear program:

$$
\min _{C_{i, t}^{\prime}, \tilde{q}_{i, t}} \sum_{t} \sum_{i}\left(\tilde{q}_{i, t}-q_{i, t}\right)_{i, t}^{2}
$$

Subject to:

(i) $\frac{p_{t} \mathrm{~F}_{t}-\tilde{Q}_{t} c_{i, t}^{\prime}}{\tilde{q}_{i, t}}=\frac{p_{t} \mathrm{~F}_{t}-\tilde{Q}_{t} c_{j, t}^{\prime}}{\tilde{q}_{j, t}} \geq 0, \forall i, j \in I, \forall t \in T$;

(ii) $\left(\tilde{q}_{i, t}-\tilde{q}_{i, t^{\prime}}\right)\left(C_{i, t}^{\prime}-C_{i, t^{\prime}}^{\prime}\right) \geq 0 \forall i \in I, \forall t, t^{\prime} \in T$;

(iii) $C_{i, t}^{\prime} \geq 0 \forall i \in I, \forall t \in T$.

(iv) $\tilde{q}_{i, t} \geq 0 \forall i \in I, \forall t \in T$.

Note the non-linear constraints in Expressions (i) and (ii). The basic idea here is to find sets of inputs that are consistent with the outputs and the model restrictions, and then choose from among those sets of inputs the ones that are closest to the observed data. This approach has the advantages of having a clear structural interpretation in terms of measurement error and of consistently incorporating the error into all relevant points in the model.

\subsection{Proof of Concept with Simulated Data}

To demonstrate that our method can distinguish between data coming from an open-access resource and data from a common-pool resource managed with individual quotas, we develop a simulated data experiment. In particular, we assume that aggregate output $F$ is generated from a 
Cobb-Douglas production function, with equal weight on inputs of total fishing effort $(Q)$ and the stock of fish. There are 100 heterogeneous firms, which each take the price of fish as exogenous. Costs are quadratic in effort, and each firm has a unique cost parameter. Following the standard Gordon-Schaefer bioeconomic model, fish stocks grow logistically. We initialize the stock of fish at $80 \%$ of its carrying capacity and simulate fifteen periods. See Appendix B for additional details, including all parameter values.

To simulate the TOC regime, we solve the optimization problem for each firm, following the model of Section 2 and the first-order condition given by Equation (2). To simulate the IFQ regime, using the same parameters, we solve for the fishery's maximum sustainable yield, invert the production function to obtain the corresponding aggregate effort level in each period, and allocate time-specific effort quotas across the 100 firms in proportion to their TOC effort shares. This general approach to simulated bioeconomic experiments, in which firms' individual behavior is a function of the resource base while their collective behavior feeds back onto the resource, follows Ferraro, Sanchirico, and Smith (2019).

We generate four simulated data sets: the two property rights regimes, each with low- and high-cost scenarios. In both cost scenarios, our linear programming results fail to reject the TOC Model, as we would expect, whereas the linear program does reject the TOC Model when behavior is governed by IFQs. Details of these results can be found in Appendix B. In summary, when subsampling from the data and computing rejection rates, as described in Section 2.2, we always fail to reject the TOC Model with data generated from the simulated open access regime, whereas we reject the model under the simulated IFQ regime at least $20 \%$ of the time with subsamples containing as little as 3 years and 5 vessels, and $100 \%$ of the time with 50 or more vessels (see appendix Table B1). Finally, computing distance to the TOC model, as described in Section 3.2, we find a distance of zero or near-zero for the simulated open access regimes, whereas distance to the TOC model is much higher in the simulated IFQ regime (Table B2), as we would expect. These results illustrate the ability, in principle, of our approach to detect departures from the TOC model.

\section{Empirical Application}

We apply our test to the Norwegian whitefish fishery using data for the period 1998 to 2007. The setting is fitting for two reasons. First, fisheries are a classic example of the tragedy of the commons, and even when regulators establish industry-wide quotas and partly restrict access to the 
fishery, open-access incentives that encourage a race to fish can persist (Homans and Wilen 1997; Smith et al. 2008; Abbott and Wilen 2011; Birkenbach et al. 2017). Second, this particular fishery experienced a management change during the sample period that strengthened property rights for portion of the fleet and thereby reduced tragedy-of-the-commons incentives. As such, we expect the TOC model to fit the data better before the policy change than after. Dividing the sample into treatment and control groups before and after the policy change allows for a comparative test of two policy regimes.

In the remainder of this section, we further describe the Norwegian fishery and the data available.

\subsection{The Norwegian Whitefish Fishery}

Norway has the largest fishing industry in Europe. Its most valuable fishery is whitefish (also known as groundfish). The Norwegian whitefish fishery includes many species, but cod, haddock and saithe (Atlantic Pollock) are the most important in terms of total volume and value. Norway's whitefish fishery is biologically separate from other major fisheries, so output from the fishery $F(Q)$ can be modeled in isolation as a single resource. The fleet targeting whitefish includes various vessel groups of different sizes and gear. Trawlers are relatively large vessels, with lengths ranging from 28 to 76 meters, and they fish in deeper off-shore waters. The coastal fleet comprises smaller vessels under 28 meters using a variety of gear such as long lines, troll nets, and Danish seine. Our sample contains only the coastal fleet, as individual vessel quotas were introduced for the trawlers at an earlier time. The management system requires that each fishing vessel is separately owned by an operator, so vessels can be taken as firms in our model.

In 1989 a total allowable catch (TAC) quota was set for the whole whitefish fishery, with the TAC divided between the trawler fleet and the coastal fleet. In 1990, a non-tradable individual vessel quota (IVQ) system was introduced for the Norwegian coastal fleet, at least theoretically. However, to ensure that the allocated quotas were fished within the coastal vessel group, an "overbooking system" was introduced in 1991, in which the sum of the individual vessels' quotas were substantially higher than the TAC for the vessel group. Consequently, the IVQ system was nonbinding, making the management more like a regulated restricted access system (RRA) than a true IVQ system. From the perspective of our theoretical model, we view this period as preserving the open-access regime, with some restrictions on technological inputs and total catch, but with no 
individual limits on catch (or effort) and with incentives promoting a race to fish. Our data (described below) begin in 1998, during this regime.

In 2003, the quota for the coastal fleet was divided into four groups by vessel length $(<11 \mathrm{~m}$, $11-15 \mathrm{~m}, 15-21 \mathrm{~m}, 21-28 \mathrm{~m})$. Thus, groups no longer needed to compete across vessel length categories. This appears to have helped the small vessels as a group, as they no longer had to compete with larger vessels for their share of the quota. However, initially, the sum of the individual quotas still exceeded the TAC (group quota). Hence, firms theoretically could catch all of their individual quota, but they still had to race other vessels of the same size class to reach their limit. Moreover, there was no guarantee they would get any quota. Effectively, the individual quotas remained upper-bound constraints.

Finally, in 2004, overbooking ended for vessels above 15 meters. Additionally, these larger coastal vessels were allowed to combine quotas from several vessels onto one, thereby introducing a form of transferability into the system. Thus, the regime for larger coastal vessels transformed to a truly binding IVQ system in 2004, while it remained an RRA system for smaller vessels. Hannesson (2013), Standal et al. (2016) and Cojocaru et al. (2019) provide further information about the fishery and the development of the management system. Our analysis will end in 2007 when an IVQ system was introduced also for vessels between 11 and 15 meters.

To summarize, from 1998 to 2002, all vessels in our data set were under an RRA regime that we expect preserved tragedy-of-the-commons incentives (as in Smith et al. 2008 and Abbott and Wilen 2011). After 2003, larger coastal vessels transitioned into an IVQ regime while the small vessels were still under an RRA regime. In between, 2003 was something of a transition year. Small vessels and large vessels were given separate group quotas, but still competed within group, a problem that may have been especially severe for small vessels.

This change in property rights regimes affords an opportunity to apply our test of the tragedy of the commons using a difference-in-differences (DD) design. We expect higher rejection rates for large coastal vessels for the 2003-7 period, relative to the 1998-2002 period, and relative to the corresponding difference for small vessels. In sensitivity analyses, we also consider omitting 2003. 


\subsection{Description of Data}

The data for the Norway coastal fleet cover the period 1998 to 2007 and come from an annual random survey conducted by the Norwegian Directorate of Fisheries of vessels with only a sample of the registered active vessels being surveyed each year. Table 1 summarizes the data. The first row shows the sample size. The second row shows the total number of vessels registered in each year (population). The total sample comprises 1,127 individual vessels from 1998 to 2007. Each vessel is identified with a unique ID. We have information on the length and weight of each vessel as well as on fishing effort and other inputs, including days at sea, operating days (days at sea plus days working at port), fuel expenditure, labor compensation, and the average number of crew members operating the vessel.

With respect to outputs, we have vessel-year data on the total quantity landed and revenues received by species (cod, haddock, saithe and other whitefish), in tons and Norwegian Krone (NOK), respectively. However, our test only requires knowing the aggregate revenue. Thus, we first create an index by summing over fish species, then sum over vessels to obtain the total sample revenue for each year, $p_{t} \widehat{\mathrm{F}}_{t}$. Then, we multiply the average sample revenue by number of total vessels in the population to obtain the aggregate revenue. Row 3 of Table 1 shows the total sample revenue. Row 4 converts this sample to an estimate of total revenue, multiplying the sample mean by the number of vessels operating. This is the value of output $p_{t} \widehat{\mathrm{F}}_{t}$ used in our test. It shows some ups and downs followed by an upward trend after 2003. The next row similarly shows the trend in sampled catch in tons.

Although it requires only annual aggregate revenue on the output side, our test requires micro-level data on the input side. Vessels are not necessarily sampled in each year and do not necessarily fish in all years anyway, so we have an unbalanced panel of vessel-level inputs. Also, reported zeros for an input indicates that these fields were left blank in the survey. Accordingly, we exclude vessels that reported both zero operating days and zero days at sea but positive labor, fuel or other operating expenses in the analysis. Table 2A shows raw data on inputs, including operating days, days at sea, person-years, labor compensation, and fuel expenditure.

\subsection{Quantifying Effort}

In taking the theoretical model to the data, a central modeling question is how to measure effort 
(or input) $q_{i, t}$, which appears as a scalar in the theoretical model. As measures of effort, we consider the following four proxies: operating days, imputed days at sea, imputed days at sea times vessel length (Length* Days), and an estimated scalar-valued function of effort based on multiple inputs. Of these, operating days, which includes days at sea as well as days processing and offloading in port, is the most straightforward proxy. Table 2B shows summary statistics for operating days as used in the model.

Our second measure is days at sea. Averaging over time, days at sea contains 81.3 fewer days fleet-wide than operating days, and there are 748 observations with positive operating days but zero reported days at sea. Since it is impossible to have zero days at sea when operating days and catch are positive, we treat these zeros as missing and replace them with imputed values when the associated operating days are positive. Details of this imputation are provided in Appendix C. The next row of Table 2B shows annual data on imputed days at sea.

Our third measure of input uses these imputed days at sea times vessel length. Rescaling fishing time by measures of vessel size is a common practice when estimating fisheries production functions, as a better measure of overall inputs (Squires 1987; Huang and Smith 2014). Table 2B also reports annual values of this product.

Our fourth and final measure of input aggregates multiple input variables into a scalarvalued function. This too is a common practice in the fisheries literature (see McCluskey and Lewison 2008 for review and discussion). We adopt a straightforward method that serves our purpose. Suppose the production function for vessel $i$ in year $t$ is

$$
\ln \left(\operatorname{Catch}_{i, t}\right)=b * \ln q_{i, t}+\lambda_{t}+e_{i, t}
$$

where $\lambda_{t}$ is a dummy which captures year effects, such as different stock levels, and $q_{i, t}$ denotes the overall effort level for vessel $i$ at year $t$, and is a sub-function of other inputs. In particular, let

$$
\begin{aligned}
& \ln \left(q_{i, t}\right)=\alpha_{2} \ln \left(\text { person-years }_{i, t}\right)+\alpha_{3} \ln \left(\text { fuel expenditure }_{i, t}\right)+ \\
& \alpha_{4} \ln \left(\text { labor compensation }_{i, t}\right)+\text { vesselid }_{i},
\end{aligned}
$$

in which person-years denotes the labor input (measured at the day level) and labor compensation is the total payment to workers on the vessel and vesselid $i$ is vessel level fixed effect that captures vessel length, tonnage, and unobserved heterogeneity in fishing skill. 
Substituting Equation (7) into (6), we estimate the combined model. Note, however, that we cannot separately identify $b$ in Equation (6) from the alphas in Equation (7). Thus, we do not identify effort to scale. This is not problematic, however, because our test treats the cost of effort as a latent function, so any arbitrary change of scale in effort can be reconciled by an offsetting change in the scale of the cost function. The results of estimating this model are shown in Appendix Table C2. The last row of table 2B shows summary statistics for this estimated value.

\subsection{Sampling Subsets of Data}

Because, in our approach, rejections are all or nothing, the presence of only one firm behaving out of step with the other firms could result in rejecting the entire data set. Likewise, if cost functions shift over time, assuming they are constant could lead to false rejections. To sidestep these issues, we follow Carvajal et al. (2013) and repeatedly sample smaller subsets of data. Sam-

pling the data allows us to consider rejection rates (percentage of data sets that do not conform to the TOC model), rather than one single all-or-nothing conclusion. We divide the entire data set into multiple subsets, with each set consisting of $N$ vessels and $T$ consecutive years, where $N \in\{5$, $10,50,100,150\}$ and $T \in\{3,6,8,10\}$. Then we separately test for consistency with the TOC model using each set. We randomly sampled 100 subsets from each $N$-by- $T$ combination, giving us a reasonable estimate of the rejection rates for each combination. To facilitate comparisons, we used the same subsample of data for each cell across models.

\subsection{Weighted Sampling and Property Rights Regime Comparison}

As discussed in section 4.1, the evolution of property rights in the Norwegian fishery motivates splitting the data into the periods of the RRA regime (1998-2002) and the period of IVQs for the coastal vessels at least 15 meters in length (2003-2007). Accordingly, we cut the data into four cells using a $2 \times 2$ design; large coastal vessels ( $\geq 15$ meters long) and small vessels $(<15 \mathrm{~m})$, before the IVQ regime (1998-2002) and after (2003-2007).

It is worth noting that, though we sub-sample by vessel size in this exercise, in the common-ratio properties for each group of each year, we keep the total input $Q_{t}$ and output $F_{t}\left(Q_{t}\right)$ across all vessels. That is, behavior of all vessels (regardless of length) still affects the optimal behavior of any one vessel because the aggregate resource stock in coastal areas is a common pool. 
In this unbalanced panel for the Norwegian coastal fleet, the administration of the random survey led to fewer surveyed vessels in earlier time periods (before 2003) than later (after 2003). When we sample subsets as described in Section 4.4 with no restrictions (where each vessel has an equal probability to be selected), the sets sampled in later periods will contain more data points than those from earlier periods. Given the nature of our test, more data points create more constraints, which automatically yields higher rejections holding all other things equal. Hence, to make sure the gap in rejection rates per group is attributed to behavioral difference under different management regimes, rather than the difference in the number of observations in the samples, we employ weighted sampling to generate comparable samples for each group.

Weighted sampling is implemented by redistributing sampling probabilities among vessels in later periods (2003-2007). Sampling probabilities for vessels with more observations (3 and 4 data points in periods 2003-2007) are reduced, and the reduced probabilities are added to vessels with fewer observations ( 1 and 2 data points), with the total probability always summing to one. The largest adjustment of the probability of a vessel is less than 0.0002 , while the original probability of a vessel being sampled is around 0.00116, so the adjustment is less than $17 \%$. After weighted sampling, the maximum difference in the number of observations between the groups

(before vs. after) is less than $0.2 \%$ (difference in observations divided by total observations in subsample sets). In our 2x2 design, our weighted sampling ensures that the large-after and largebefore groups have similar numbers of observations, as do the small-after and small-before groups. This helps to balance the number of observations among groups to generate credible DD results.

As discussed in Section 4.1, data generated from the IVQ regime is not expected to be consistent with the TOC model, especially for large vessels. Accordingly, we first take the difference of rejections between the large-after and large-before groups and likewise for the small-after and small-before groups. Finally, we take the difference in differences, to infer the effects of the change in property rights regime. We expect the after-before difference for large vessels will be higher than those for small vessels.

\section{Results}

In this section, we first present results of the principle test as described in Section 2. We then present results with sampling errors (Section 3.1) and statistical tests based on distance from revealed marginal costs to model-consistent marginal costs (Section 3.2), including results based on 
our DD design. Finally, we present complementary parametric tests of improved fishery outcomes using our DD design.

\subsection{Results of Test Pooling all Data}

We first implement our tests on all data pooled together. In this case, we expect to reject TOC behavior as we are including post-reform data in the analysis. Tables 3A-3D present results using the principle test of Section 2 using four respective proxies for effort: operating days, imputed days at sea, imputed days at sea times length, and estimated total effort. Each cell in the tables shows the rejection rate for a sample of 100 data sets for $N$ vessels and $T$ consecutive years, for varying $N$ and $T$. For small $N$ and $T$, we generally cannot reject the TOC model in most samples. Note, however, that the rejection rates generally are increasing in $N$ (moving down the rows) and $T$ (moving to the right across columns). Indeed, when more than 100 vessels are considered for longer than 6 years, the rejection rates approach one. This trend follows mechanically in expectations, as the number of equations and inequalities to satisfy is increasing in these parameters, so exceptions to this rule are due to random sampling. More substantively, the trend also is consistent with the idea that, as we increase $T$, we risk pooling different cost functions as well as data from the period after the property rights reform, when the TOC model is unlikely to apply. Overall, these results indicate that the behavior of vessels/fishermen in our sample cannot be explained by the TOC model when a large number of observations are included, including observations taken from the post-reform period.

Additionally, we test consistency with the model with sampling errors (as discussed in Section 3.1). The range of sampling errors we adopted is [-5\%, 5\%]. That is, we restrict the multiplier $\gamma_{t}$ to be between $[0.95,1.05] .{ }^{3}$ Given that the average revenue in our sample is 1.4 million NOK (around 166,000 USD) per year per vessel, this bandwidth allows for an average adjustment to the revenue of 67,000 NOK (around 8,000 USD) per year per vessel. Tables 4A-4D present the results. As we would expect with added flexibility, rejection rates of the TOC model allowing for

\footnotetext{
${ }^{3}$ Because of the large number of missing values in the sampled data, we apply narrow boundaries to the permissible sampling error. Our unbalanced panel data of the Norwegian whitefish fishery has $79.3 \%$ of data points missing. The amount of missing data substantially reduces nonempty constraints in our test, which makes it easy to find marginal costs that are consistent with the model. Allowing for a larger adjustment to the total revenue makes the tests even less stringent and reduces the rejection rates towards zero. For instance, all rejection rates are zero when the boundary is $10 \%$ in our case.
} 
sampling errors are slightly lower than those in the basic model (comparing like cells). But the previous patterns remain. First, rejection rates still increase in $N$ and $T$. Second, when more than 100 vessels are considered for longer than 6 years, the rejection rates still approach one. This result provides additional support for the conclusion that behavior of vessels/fishermen in our overall sample cannot be explained by the TOC model when a fair number of observations are included.

We also tested the model allowing minimal behavioral errors and deriving a K-S test statistic (Section 3.2). The first Column of Table 5 presents the results for the combined data. For each of the four measures of effort, it shows an adjusted mean squared error $\delta_{i, t}^{2}$ per cell, per thousand constraints to be satisfied. ${ }^{4}$ To gauge the scale of these estimated errors, the mean marginal cost is about 4.5 when effort is measured by operating days, so these errors are fairly small. This scaling differs by measure of effort making comparisons difficult, but, across measures, the mean absolute value of the errors is about $5 \%$ of marginal costs, the mode is $0 \%$, and the $90^{\text {th }}$ percentile error is $10-17 \%$ of marginal costs. We also conducted the KS test of Section 3.2 using the entire data set. For all four measures of effort, we reject the TOC model with the pooled data with pvalues $<0.01$. Results from these tests confirm our observation from the rejection rates in Tables 3 and 4.

\subsection{Results Comparing Property Rights Regimes}

Recall that all vessels operated under RRA before 2003. Throughout the period (19982007) in our sample, a TAC for all participants was in place, but in 2003 the quota was distributed to groups based on vessel length. After 2003, small vessels remained operating under a total allowable catch and the RRA regime, while large vessels transitioned to an IVQ regime. This make the small vessels a good control group for the large vessels. Whereas there is competition among vessels under a group quota, competition among large vessels is reduced under the property-rights based management of IVQs because each large vessel is guaranteed its share of the total catch.

\footnotetext{
${ }^{4}$ This adjustment is necessary for comparisons across cuts of the data in the next subsection, as it accounts for the changing number of constraints. For example, if there are $N$ vessels and $T$ years of data, and if there were no missing data, there would be $N T$ cells used as the denominator for the simple mean squared error, but $N\left(T^{2}-T\right) / 2+T\left(N^{2}-N\right) / 2=N T(N+T-2) / 2$ constraints used as the denominator for the adjusted mean squared error. Our actual calculation accounts for missing values in the formula.
} 
The effectiveness of the property-rights approach of IVQs over the non-property-rights based approach of RRA motivates a DD design for our empirical application.

Table 6A - 6D present rejection rates per group using the weighted sampling described above in Section 4.5. The results indicate that, after the reform, large vessels experience a higher relative increase in rejection rates of the TOC model compared to small vessels. That implies the IVQ regime generates fishing behavior that is less consistent with the TOC model than the RRA regime. In other words, the IVQ regime nudges fishing behavior away from Nash behavior more effectively than does RRA, as one would expect.

Note that after we split the data into four groups, there are fewer observations to sample from per group. Because the weighted sampling only controls for the difference in the number of observations of each paired group (before vs. after), but not the magnitude of observations in samples, the levels of rejection rates are sensitive to the number of observations in the respective subgroups, but the difference and DD results reflect the overall change in management regimes and are more stable.

We also replicated these tests omitting 2003, which was a transition year and arguably was different from the subsequent 2004-7 period, when large vessels were under the TAC. Our results are qualitatively similar using this approach and are available upon request.

Interestingly, looking only at small vessels, we observe a decrease in rejection rates in the 2003-7 period. Taken in isolation, this suggests that the behavior of small vessels actually moved closer to the Nash TOC behavior after 2003. One possible explanation for this finding is that the IFQ for large vessels increased the potential rents to smaller vessels, but because they remained under a group quota the smaller vessels thus had a greater incentive to (over) exploit the commons. In the following subsection, we present reduced-form evidence supporting this hypothesis.

Columns 2-5 of Table 5 show the results of allowing minimal behavioral errors within each segment of the data (Section 3.2). Comparing across vessel sizes and property rights regimes for any one measure of effort, we see a notable increase in the errors and, to some extent, the probability of rejecting the model in the "after" period relative to the "before" period, as we would expect. However, as a rule p-values cannot be meaningfully compared across models. Focusing on the adjusted MSE, we see greater increases for the large vessels, as expected. The final column shows the DD in the MSE, which is positive for all four measures of effort. 


\subsection{Supplemental Evidence and Discussion}

As mentioned above, there is some evidence that, even as large vessels moved away from Nash TOC behavior after 2003, the behavior of small vessels became, if anything, closer to the TOC. One possible explanation for this finding is that, before 2003, small vessels could not compete well with large vessels in the race to fish, whereas after 2003 separating out the TAC for the small vessels reduced the competition from large vessels, thus securing a potential economic rent for the group as a whole. However, without property rights to individual quotas, that potential rent spurred the race to fish among small vessels.

Under the tragedy of the commons, effort $(q)$ increases until, with a large number of vessels, the marginal cost of effort equals average returns instead of marginal returns, eliminating resource rents. After 2003, binding IFQs should reduce effort for large vessels and increase average returns. Meanwhile, reduced competition could potentially increase rents for small vessels, leading to a ceteris paribus increase in average returns, but, without binding quotas, small vessels would be expected to respond by collectively increasing effort, thereby reducing average returns back to marginal costs in equilibrium.

To further explore this possibility, we first compare effort over time by vessel size. At the extensive margin, Figure 1 compares the number of small and large vessels across years. It shows a marked increase in the total number of small vessels in 2003, whereas there is little change in the number of large vessels. Furthermore, at the intensive margin, Figure 2 shows that small vessels increased their average effort, whereas larger vessels decreased effort sharply in 2003 and then stabilized. This new entry of small vessels and their additional effort may have been induced by increased economic rent after the division of the quota, which we would expect to then dissipate these rents.

Next, we explore whether large vessels had better returns for their effort in 2003. We estimate the returns to effort using a simple reduced form DD regression, as in Smith et al. (2006). In particular, we regress

$$
\begin{aligned}
\ln \left(H_{i, f, t}\right)= & \alpha+\left(\beta_{0}+\beta_{1} * \text { POST }_{t}+\beta_{2} * L A R G E_{i, f}+\beta_{3} * \text { POST *LARGE }\right) * \\
& \ln \left(q_{i, t}\right)+\gamma_{f}+\delta_{t}+\varepsilon_{i, f, t} .
\end{aligned}
$$


where $H_{i, f, t}$ is the outcome (revenue, catch in tons, or price) for vessel $i$ of length classification $f$ in year $t$, POST is an indicator for post-2003, LARGE is an indicator for length $\geq 15$ meters, $q_{i, t}$ is effort measured in imputed days at sea, $\gamma_{f}$ is a vector of dummies for four vessel length classifications, and $\delta_{t}$ is a vector of year dummies. The parameter of interest, $\beta_{3}$ captures the DD effect for the post-2003 change for large vessels, relative to the change for small vessels, on catch per unit effort.

Table 7 displays the results, with standard errors clustered by year and length category. The first column shows the effects using total revenue as the outcome. It shows a statistically significant increase for revenue, per day at sea, of 2.8 percentage points (pp) for large vessels relative to small. This bottom-line result suggests that large vessels do indeed benefit more from the regulation, while small vessels simply dissipate their potential rents with increased effort. The remaining columns decompose this result. The next five columns show the DD effect on catch, in tons, for total fish and separately for each species. The point estimate of $2.2 \mathrm{pp}$ for total catch per day is statistically significant and in line with the revenue effect of $2.8 \mathrm{pp}$. Interestingly, there are larger and statistically significant increases in the catch for cod, haddock, and saithe, coupled with a decline in other species, perhaps indicating "high grading" or targeting high-value species to get the greatest value from the quota with the others being caught exclusively as bycatch.

The last five columns show the effect on price, or total revenue divided by tons caught. As large and small vessels are selling into the same market, with the same quality-adjusted prices, differences in "price," as defined here, between vessel classes can be interpreted as a difference in quality, or a "movement along" a price-quality hedonic price function. Increased prices are consistent with previous studies arguing that slowing the race to fish can increase per unit prices through quality or avoidance of market gluts (Grafton, Squires, and Fox 2000; Homans and Wilen 2005). We find smaller effects, though statistically significant for cod and saithe, again indicating potential high grading, with bigger vessels having the opportunity to more selectively target larger, higher-value fish. All the results from Table 5 are qualitatively similar when we omit 2003, which might be interpreted as a transition year between property rights regimes.

To complement this difference-in-difference strategy, we test for parallel trends, conduct falsification tests, and estimate event studies. We fail to reject the hypothesis of no differences in pre-trends for any of the outcomes. For falsification tests, we place a placebo treatment in 1999 or 
2000 and estimate the DD coefficient for each outcome restricting the post-treatment sample to years through 2002. We fail to reject the null of a zero-treatment effect for all placebo designs and outcome measures. Figures C1-C9 in the appendix display standard event study graphs. They show little evidence of pre-period trends and persistent increases in quantity and price post-2003 for large vessels relative to small, especially for cod and saithe.

These patterns support the findings of our non-parametric test. As seen in Section 5.2, the data move further away from the Nash TOC model after the 2003 reform, especially for large vessels relative to small. The patterns presented here provide additional intuitive evidence consistent with those tests. They also support the idea that improvements in management for one group (here, restricting access for the large vessels) may not spill over into improvements for other groups, if they simply maintain rent-dissipating behavior. This interpretation is in line with the finding in Homans and Wilen (1997) that certain types of non-property-rights-based management may actually induce a race to fish. It also is consistent with the findings in Kroetz et al. (2015) that policy with well-intentioned social objectives to preserve small-scale fishing capacity can reduce overall economic efficiency and rents in fisheries.

\section{Conclusion}

Work to date on testing the tragedy of the commons has focused either on policy outcomes involving the state of shared resources or, when using behavioral data, has relied on highly structural models involving numerous maintained assumptions. Drawing on applications of revealed preference theory to behavioral data, including Carvajal et al. (2013) on the Cournot model, we derive non-parametric tests of the tragedy of the commons using minimal assumptions.

We apply this new test to the Norwegian groundfish fishery. Overall, we find the behavior of individual vessels of the Norwegian Coastal Fishery does not conform to the model of the tragedy of the commons. More importantly, we find that rejection rates are larger after property rights reforms, especially for the large vessels that received stronger property rights. Additionally, using a distance-based metric, we find that behavior moves further from the pure TOC model after the reforms. Our results suggest that Norwegian policy has changed behavior and ameliorated the commons problem for large coastal vessels at least to some extent.

Our methodological innovations that build on the principle test of the TOC model have practical significance. By providing methods that account for sampling and/or measurement errors 
in aggregate output and input data and that can gauge distances to the TOC model with associated statistical tests, our approach is broadly applicable to applied problems that are likely to arise in regulated common-pool resource settings. For example, in most settings inputs are very likely to be measured with error, often coming from self-reports or other surveys.

Although the fishery provides an iconic illustration of the commons, our approach can also be applied to a wide range of other resources. Candidate common-pool resource problems include clearcutting forests or fuelwood collection under different governance structures; grazing livestock on common land; siting offshore aquaculture facilities; pumping groundwater; oil, gas, and other mineral extraction; collective management of infectious diseases; pesticide resistance; and controlling invasive species.

Just as our specific model can be applied to other common resources, our general approach can be extended and applied to other behavioral rules and settings beyond common-pool resources. While our test of the TOC model pertains to the average-return game with Nash behavior, Banzhaf and Liu (2016) extend the TOC model to the case of conjectural variations (rather than Nash behavior) as suggested by Cornes and Sandler (1983). Because our empirical application involves hundreds of players, we expect Nash behavior to be more relevant than conjectural variations, but small numbers of players are more prevalent in other resource settings such as unitization of oil fields or groundwater extraction from a local aquifer. Moreover, the game can be modified to apply to the average cost (rather than average returns) game, where agents choose outputs and pay average costs. Such problems are relevant to many problems involving the division of joint costs, such as telephony. Looking past open-access resources, our approach could be applied to collective farms or other enterprises whenever outputs are divided proportionately to inputs (Sen 1966). Alternatively, simply by adapting the objective function, numerous other sharing rules could be considered and the respective behavior tested, including equal per capita sharing, which tends to lead to shirking rather than over exploitation. In this way, our approach potentially extends to many surplus-sharing games.

Whatever the application, policies to regulate the commons are extremely diverse, so it is natural to ask whether some policy configurations move behavior away from the tragedy of the commons more than others. Our approach can facilitate comparative work on the behavioral con- 
sequences of different policy interventions and other approaches to governing common-pool resources. Economists often imagine a stylized first-best policy to ration access to the commons, with perfectly secure and transferable individual property rights. That first-best policy is juxtaposed with a complete lack of policy under pure open access. However, real-world policies are configured in myriad ways that differ from theoretical first-best policies. For example, in fisheries, rights-based systems differ along dimensions of the security of the property right, the length of term, transferability, and a number of other restrictions that often come about as political compromises to address community or industry concerns (Asche et al 2018). Moreover, property rightsbased policies tend to build on existing institutions, which already ration access to the commons to some degree and create incentives differing from those of pure open access (Birkenbach, Kaczan, and Smith 2017). In general, our model and distance-based metric have the potential to examine whether different policies induce more or less commons-like behavior.

Such comparative work using our methods potentially has broad interdisciplinary appeal. Although economists have studied the commons problem for more than a century, Hardin's (1968) coining of the term "tragedy of the commons" in the general scientific literature helped to garner attention from ecologists, other environmental scientists, non-economics social scientists, legal scholars, and systems modelers (Banzhaf 2020, Frischman et al. 2019). Subsequently, Ostrom (1990) criticized Hardin for ignoring the potential for self-organized solutions to the commons and ultimately helped to develop a new interdisciplinary field to investigate problems in the commons. Within this new field, there are widely disparate normative views on what governing the commons ought to achieve and thus what outcomes should be measured. Economists are often stereotyped as having a singular focus on formal property rights-based solutions to the commons and the generation of resource rents without regard for potential unintended consequences on local communities (Young et al. 2018). Our approach offers a neutral behavioral test of interest across disciplines that does not depend on how different scholars attach normative weight to resource rents, distributional outcomes, employment, or any other indicators of community well-being. 


\section{References}

Abbott, Joshua K., and James E. Wilen. 2011. "Dissecting the tragedy: a spatial model of behavior in the commons." Journal of Environmental Economics and Management 62(3): 386-401.

Afriat, S.N. 1967. "The Construction of a Utility Function from Demand Data." International Economic Review 8: 67-77.

Afriat, S.N. 1972. "Efficiency Estimation of Production Functions." International Economic Review 13(3): 568-98.

Asche, Frank, Taryn M. Garlock, James L. Anderson, Simon R. Bush, Martin D. Smith, Christopher M. Anderson, Jingjie Chu, Karen A. Garrett, Audun Lem, Kai Lorenzen, Atle Oglend, Sigbjørn Tveteras, and Stefania Vannuccini. 2018. "Three Pillars of Sustainability in Fisheries." Proceedings of the National Academy of Sciences 115(44): 11221-25.

Ayres, Andrew B., Kyle C. Meng, and Andrew Plantinga. 2019. "Do Property Rights Alleviate the Problem of the Commons? Evidence from California Groundwater Permits." NBER Working Paper 26268.

Balthrop, Andrew T., and Kurt E. Schnier. 2016. "A Regression Discontinuity Approach to Measuring the Effectiveness of Oil and natural Gas Regulation to Address the Common-Pool Externality." Resource and Energy Economics 44: 118-38.

Banzhaf, H. Spencer. 2020. A History of Pricing Pollution (or, Why Pigouvian Taxes are not Necessarily Pigouvian). NBER Working Paper w27683.

Banzhaf, H. Spencer, and Yaqin Liu. 2016. "Notes to Nonparametric Test of the Tragedy of the Commons." Working Paper. Georgia State University.

Birkenbach, Anna M., David J. Kaczan, and Martin D. Smith. 2017. "Catch Shares Slow the Race to Fish." Nature 544: 223-26.

Brozović, Nicholas, David L. Sunding, and David Zilberman. 2010. "On the Spatial Nature of the Groundwater Pumping Externality." Resource and Energy Economics 32(2): 154-64.

Burlig, Fiona, Louis Preonas, and Matt Woerman. 2020. "Groundwater, Energy, and Crop Choice." Working Paper. University of Chicago.

Carvajal, Andres, Rahul Deb, James Fenske, and John K. H. Quah. 2013. "Revealed Preference Tests of the Cournot Model." Econometrica 81: 2351-79.

Chambers, Christopher P., and Federico Echenique. 2016. Revealed Preference Theory. Cambridge University Press.

Ciriacy-Wantrup, S.V., and Richard C. Bishop. 1975. "'Common Property' as a Concept in Natural Resource Policy." Natural Resources Journal 15: 713-27.

Cojocaru, Andreea, Frank Asche, Ruth B. Pincinato and Hans-Martin Straume. 2019. "Where Are the Fish Landed? An Analysis of Landing Plants in Norway." Land Economics 95(2): 246-57. 
Cornes, Richard, and Todd Sandler. 1983. "On Commons and Tragedies." American Economic Review 73(4): 787-92.

Cornes, Richard, and Todd Sandler. 1996. The Theory of Externalities, Public Goods, and Club Goods. Cambridge University Press, $2^{\text {nd }}$ ed.

Costello, Christopher, and Corbett A. Grainger. 2018. "Property rights, regulatory capture, and exploitation of natural resources." Journal of the Association of Environmental and Resource Economists 5(2): 441-79.

Dasgupta, Partha S., and Geoffrey M. Heal. 1979. Economic Theory and Exhaustible Resources. Cambridge University Press.

Dietz, Thomas, Elinor Ostrom, and Paul C. Stern. 2003. "The Struggle to Govern the Commons." Science 302(5652): 1907-12.

Diewert, W. Erwin. 1973. "Afriat and Revealed Preference Theory." Review of Economic Studies 40: 419-25.

Felthoven, Ronald G., William C. Horrace, and Kurt E. Schnier. 2009. "Estimating Heterogeneous Capacity and Capacity Utilization in a Multi-Species Fishery." Journal of Productivity Analysis 32: 173-89.

Ferraro, Paul J., James N. Sanchirico, and Martin D. Smith. 2019. "Causal Inference in Coupled Human and Natural Systems." Proceedings of the National Academy of Sciences 116(12): 5311-18.

Frischman, Brett M., Alain Marciano, and Giovanni Batista Ramello. 2019. "Retrospectives: Tragedy of the Commons after 50 Years." Journal of Economic Perspectives 33(4): 21128.

Gordon, H. Scott. 1954. "The Economic Theory of a Common-Property Resource: The Fishery. Journal of Political Economy 62:124-42.

Grafton, R. Quentin, Dale Squires, and Kevin J. Fox. 2000. "Private property and economic efficiency: a study of a common-pool resource." The Journal of Law and Economics 43(2): 679-714.

Hands, D. Wade. 2014. "Paul Samuelson and Revealed Preference Theory." History of Political Economy 46(1): 85-116.

Hannesson, Rögnvaldur. 2013. "Norway's Experience with ITQs." Marine Policy 37: 264-69.

Hardin, Garrett. 1968. "The Tragedy of the Commons." Science 162: 1243-48.

Huffaker, Ray G., and James E. Wilen. 1991. "Animal Stocking under Conditions of Declining Forage Nutrients." American Journal of Agricultural Economics 73(4): 1213-23.

Homans, Frances R., and James E. Wilen. 2005. "Markets and rent dissipation in regulated open access fisheries." Journal of Environmental Economics and Management 49(2): 381-404. 
Huang, Ling, and Martin D. Smith. 2014. "The Dynamic Efficiency Costs of Common-Pool Resource Exploitation." American Economic Review 104: 4071-4103.

Kirkley, James, Catherine J. Morrison Paul, and Dale Squires. 2002. "Capacity and Capacity Utilization in Common-Pool Resource Industries." Environmental and Resource Economics 22: 71-97.

Kroetz, Kailin, James N. Sanchirico, and Daniel K. Lew. 2015. "Efficiency costs of social objectives in tradable permit programs." Journal of the Association of Environmental and Resource Economists 2(3): 339-66.

Libecap, Gary D., and Steven N. Wiggins. 1984. "Contractual Responses to the Common Pool: Prorationing of Crude Oil Production." American Economic Review 74(1): 87-98.

McCluskey, Shannon M., and Rebecca L. Lewison. 2008. "Quantifying Fishing Effort: A Synthesis of Current Methods and their Applications." Fish and Fisheries 9: 188-200.

Ostrom, Elinor. 1990. Governing the Commons: The Evolution of Institutions for Collective Action. Cambridge University Press.

Ostrom, Elinor. 2009. "Building Trust to Solve Commons Dilemmas: Taking Small Steps to Test an Evolving Theory of Collective Action." In Games, Groups, and the Global Good, ed. by Simon Levin, pp. 207-28. Springer.

Sen, Amartya K. 1966. "Labour Allocation in a Cooperative Enterprise." Review of Economic Studies 33: 361-71.

Smith, Martin D., Junjie Zhang, and Felicia C. Coleman. 2006. "Effectiveness of Marine Reserves for Large-scale Fisheries Management." Canadian Journal of Fisheries and Aquatic Sciences 63(1): 153-64.

Smith, Martin D., Junjie Zhang, and Felicia C. Coleman. 2008. "Econometric modeling of fisheries with complex life histories: avoiding biological management failures." Journal of Environmental Economics and Management 55(3): 265-280.

Squires, Dale. 1987. "Fishing effort: Its testing, specification, and internal structure in fisheries economics and management." Journal of Environmental Economics and Management 14(3): 268-282.

Standal, Dag, Signe Annie Sønvisen, and Frank Asche. 2016. "Fishing in Deep Waters: The Development of a Deep-Sea Fishing Coastal Fleet in Norway." Marine Policy 3: 1-7.

Stavins, Robert N. 2011. "The Problem of the Commons: Still Unsettled after 100 Years." American Economic Review 101(1): 81-108.

Varian, Hal R. 1982. "The Nonparametric Approach to Demand Analysis." Econometrica 50(4): 945-73.

Varian, Hal R. 1984. "The Nonparametric Approach to Production Analysis." Econometrica 52(3): 579-97.

Varian, Hal R. 1985. "Non-Parametric Analysis of Optimizing Behavior with Measurement Error." 
Journal of Econometrics 30: 445-58.

Weitzman, Martin. 1974. "Free Access vs. Private Ownership as Alternative Systems for Managing Common Property." Journal of Economic Theory 8: 225-34.

Young, Oran R., D.G. Webster, Michael E. Cox, Jesper Raakjær, Lau Øfjord Blaxekjær, Níels Einars-son, Ross A. Virginia, et al. 2018. "Moving Beyond Panaceas in Fisheries Governance." Proceedings of the National Academy of Sciences 115(37): 9065-73. 
Figure 1. Extensive margin: Large and small vessels before and after the policy change

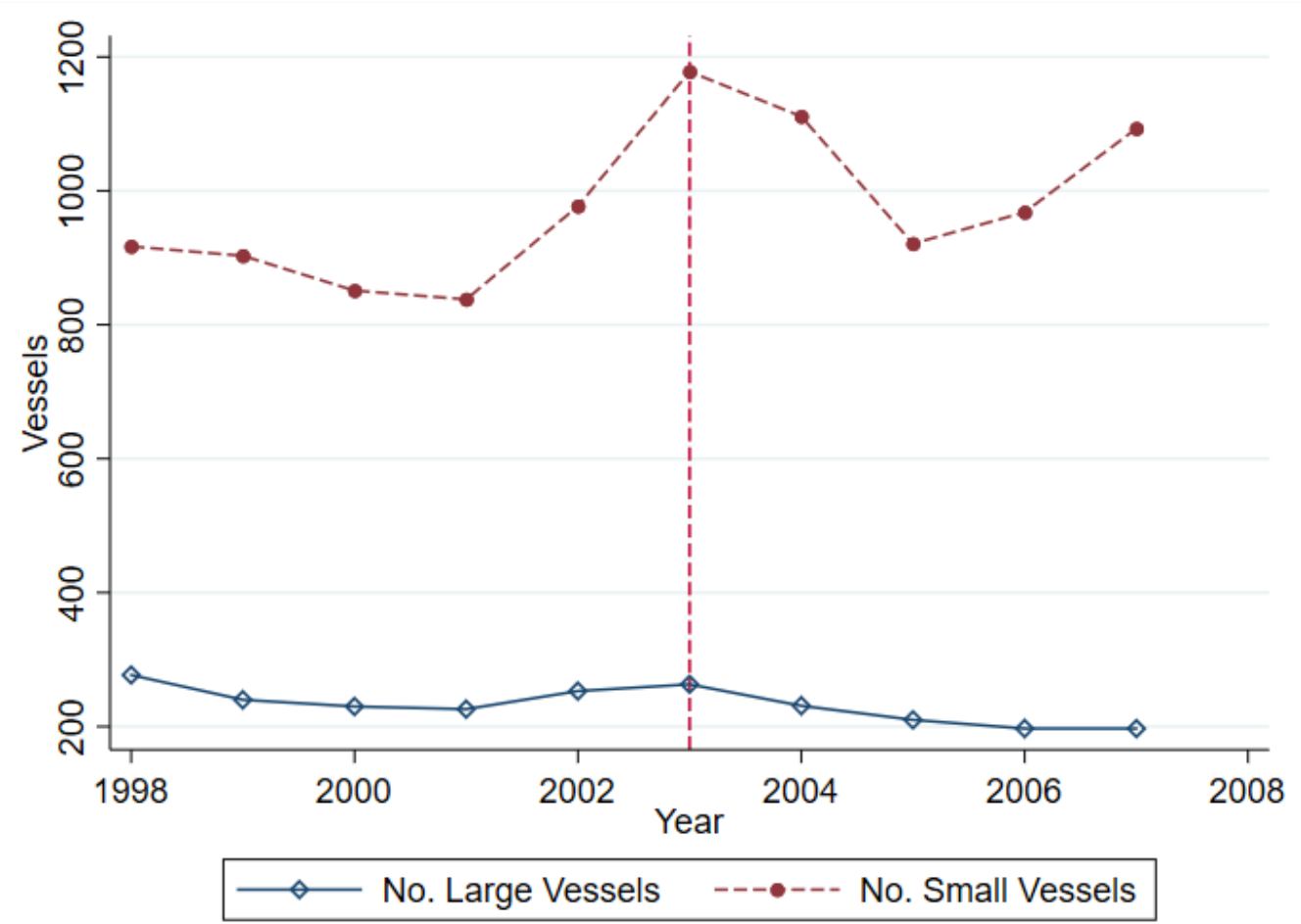

Figure 2. Intensive margin: Days at sea for large and small vessels before and after the policy change

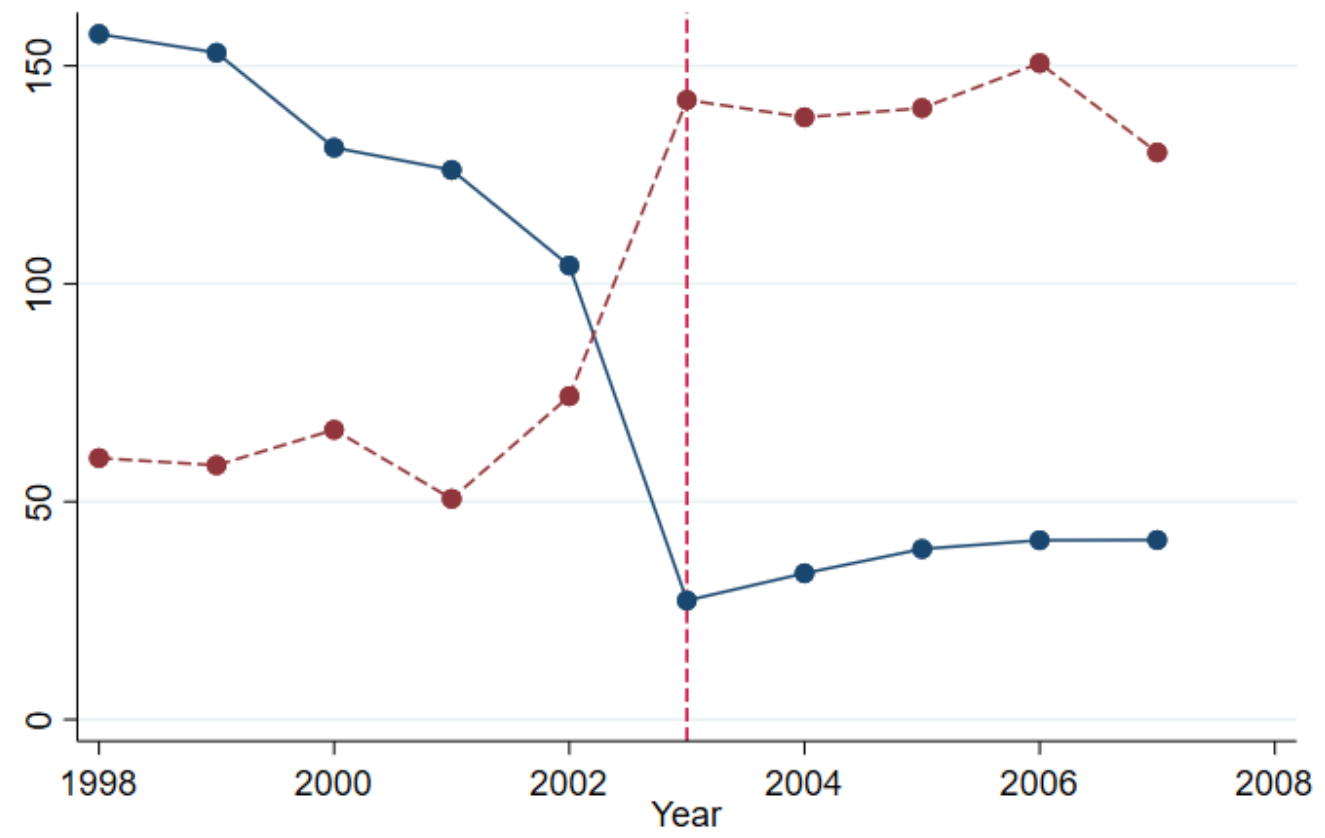

Avg days per large vessel $\quad---\bullet--$ Avg days per small vessel 
Table 1. Summary Statistics for Selected Output Variables

\begin{tabular}{|c|c|c|c|c|c|c|c|c|c|c|c|}
\hline Variable & & 1998 & 1999 & 2000 & 2001 & 2002 & 2003 & 2004 & 2005 & 2006 & 2007 \\
\hline \multicolumn{2}{|l|}{ Obs. } & 307 & 321 & 328 & 323 & 316 & 279 & 321 & 306 & 317 & 359 \\
\hline \multicolumn{2}{|l|}{ Population } & 1193 & 1143 & 1081 & 1063 & 1230 & 1441 & 1342 & 1131 & 1165 & 1290 \\
\hline \multicolumn{2}{|l|}{$\begin{array}{l}\text { Sampled annual } \\
\text { value (100 mil. } \\
\text { NOK) }\end{array}$} & 3.61 & 3.67 & 3.67 & 3.91 & 3.98 & 4.54 & 4.61 & 4.68 & 6.58 & 7.40 \\
\hline \multicolumn{2}{|l|}{$\begin{array}{l}\text { Total annual value } \\
\text { (100 mil. NOK) }\end{array}$} & 17.64 & 14.91 & 13.83 & 15.60 & 14.33 & 12.58 & 13.55 & 14.65 & 19.62 & 19.30 \\
\hline \multicolumn{2}{|l|}{$\begin{array}{l}\text { Sampled annual har- } \\
\text { vest (10 million kg) }\end{array}$} & 4.17 & 4.62 & 4.94 & 5.31 & 5.81 & 6.64 & 7.84 & 8.23 & 8.43 & 9.25 \\
\hline \multirow{4}{*}{$\begin{array}{l}\text { Cod } \\
\text { (thousand kg) }\end{array}$} & Mean & 77.7 & 55.2 & 45.0 & 48.3 & 52.2 & 51.5 & 59.4 & 72.0 & 85.4 & 73.7 \\
\hline & $\mathrm{SD}$ & 87.2 & 60.3 & 53.6 & 51.2 & 38.5 & 38.3 & 45.4 & 63.2 & 72.3 & 66.6 \\
\hline & Min & 0.1 & 0.9 & 0.6 & 0.2 & 0.1 & 0.2 & 0.1 & 0.2 & 0.3 & 0.0 \\
\hline & Max & 471.4 & 411.1 & 581.8 & 334.6 & 332.6 & 299.3 & 294.6 & 452.0 & 444.4 & 451.3 \\
\hline \multirow{4}{*}{$\begin{array}{l}\text { Haddock } \\
\text { (thousand kg) }\end{array}$} & Mean & 19.8 & 10.7 & 9.0 & 11.4 & 12.7 & 12.6 & 11.4 & 16.7 & 17.7 & 21.4 \\
\hline & $\mathrm{SD}$ & 38.3 & 21.9 & 19.7 & 14.3 & 26.9 & 32.7 & 21.3 & 30.4 & 28.2 & 38.7 \\
\hline & Min & 0.0 & 0.0 & 0.0 & 0.0 & 0.0 & 0.0 & 0.0 & 0.0 & 0.0 & 0.0 \\
\hline & Max & 204.3 & 188.1 & 211.3 & 92.4 & 251.3 & 416.2 & 158.5 & 260.5 & 185.0 & 310.8 \\
\hline \multirow{4}{*}{$\begin{array}{l}\text { Saithe } \\
\text { (thousand kg) }\end{array}$} & Mean & 29.9 & 26.3 & 22.8 & 24.7 & 19.7 & 23.2 & 22.8 & 31.9 & 50.1 & 47.3 \\
\hline & SD & 68.9 & 49.5 & 32.9 & 42.6 & 37.8 & 33.3 & 38.0 & 68.5 & 101.6 & 101.6 \\
\hline & Min & 0.0 & 0.0 & 0.0 & 0.0 & 0.0 & 0.0 & 0.0 & 0.0 & 0.0 & 0.0 \\
\hline & Max & 574.1 & 418.7 & 251.7 & 420.0 & 321.1 & 197.3 & 199.2 & 716.4 & 873.8 & 943.7 \\
\hline \multirow{4}{*}{$\begin{array}{l}\text { Other } \\
\text { (thousand kg) }\end{array}$} & Mean & 70.4 & 58.6 & 91.3 & 51.9 & 40.5 & 41.1 & 32.8 & 45.3 & 61.9 & 71.7 \\
\hline & SD & 248.2 & 212.3 & 302.6 & 178.1 & 131.9 & 94.7 & 77.7 & 110.4 & 162.4 & 263.9 \\
\hline & Min & 0.0 & 0.0 & 0.0 & 0.0 & 0.0 & 0.0 & 0.0 & 0.0 & 0.0 & 0.0 \\
\hline & Max & $1,807.2$ & $1,859.2$ & $2,203.4$ & $1,864.4$ & $1,409.4$ & 644.3 & 673.4 & 899.4 & $2,014.3$ & $2,482.1$ \\
\hline
\end{tabular}


Table 2A. Summary Statistics for Selected Input Variables (Raw Data)

\begin{tabular}{|c|c|c|c|c|c|c|c|c|c|c|c|}
\hline Variable & & 1998 & 1999 & 2000 & 2001 & 2002 & 2003 & 2004 & 2005 & 2006 & 2007 \\
\hline \multicolumn{2}{|c|}{ Obs. } & 69 & 72 & 80 & 76 & 71 & 279 & 321 & 306 & 317 & 359 \\
\hline \multirow[t]{4}{*}{ Operating days } & Mean & 268.2 & 262.0 & 268.5 & 253.8 & 244.2 & 213.3 & 193.8 & 220.9 & 227.4 & 210.1 \\
\hline & SD & 32.6 & 41.1 & 41.1 & 45.2 & 44.0 & 54.7 & 51.7 & 56.2 & 57.0 & 53.6 \\
\hline & Min & 204.0 & 176.0 & 190 & 107 & 146 & 99.0 & 83.0 & 90.0 & 93.0 & 90.0 \\
\hline & Max & 338.0 & 364.0 & 348 & 338 & 342.0 & 354.0 & 342.0 & 345.0 & 355.0 & 338.0 \\
\hline \multirow[t]{4}{*}{ Days at sea } & Mean & 219.4 & 211.4 & 198.3 & 175.5 & 178.2 & 168.7 & 168.8 & 178.3 & 189.5 & 168.9 \\
\hline & $\mathrm{SD}$ & 33.2 & 40.0 & 50.1 & 42.8 & 46.6 & 46.9 & 46.0 & 58.7 & 56.2 & 53.9 \\
\hline & Min & 152.0 & 117.0 & 60.0 & 50.2 & 95.0 & 72.0 & 77.0 & 55.0 & 72.0 & 68.2 \\
\hline & Max & 295.0 & 322.0 & 343.0 & 335.0 & 287.0 & 336.0 & 324.0 & 330.0 & 345.0 & 325.0 \\
\hline \multirow[t]{4}{*}{ Person years } & Mean & 2.3 & 2.2 & 2.1 & 2.2 & 2.1 & 2.2 & 2.1 & 2.3 & 2.4 & 2.4 \\
\hline & SD & 1.8 & 1.8 & 1.8 & 1.6 & 1.6 & 1.4 & 1.3 & 1.5 & 1.5 & 1.5 \\
\hline & Min & 1.0 & 1.0 & 1.0 & 1.0 & 1.0 & 1.0 & 1.0 & 1.0 & 1.0 & 1.0 \\
\hline & Max & 12.0 & 12.0 & 12.7 & 11.0 & 12.6 & 10.7 & 8.1 & 10.0 & 8.1 & 9.0 \\
\hline \multirow{4}{*}{$\begin{array}{l}\text { Labor } \\
\text { compensation } \\
\text { (thousand NOK) }\end{array}$} & Mean & 637.3 & 607.6 & 574.8 & 652.3 & 593.7 & 511.2 & 607.4 & 772.3 & 1025.8 & 1015.9 \\
\hline & SD & 799.9 & 808.9 & 791.9 & 821.6 & 592.5 & 480.4 & 562.8 & 721.6 & 937.6 & 979.2 \\
\hline & Min & 65.5 & 81.5 & 65.8 & 63.1 & 109.3 & 104.1 & 108.0 & 149.1 & 141.5 & 158.2 \\
\hline & Max & $5,161.4$ & 6,658.9 & $5,930.7$ & $6,151.7$ & 4,918.5 & $3,906.7$ & $4,606.4$ & 4973.9 & 6920.2 & 7184.6 \\
\hline \multirow{4}{*}{$\begin{array}{l}\text { Fuel expenditure } \\
\text { (thousand NOK) }\end{array}$} & Mean & 47.9 & 52.3 & 80.6 & 70.6 & 59.8 & 59.7 & 72.6 & 108.0 & 135.5 & 121.6 \\
\hline & SD & 73.0 & 91.9 & 161.3 & 127.3 & 108.1 & 92.6 & 97.9 & 163.7 & 177.8 & 194.1 \\
\hline & Min & 3.0 & 3.4 & 1.5 & 4.6 & 3.2 & 1.3 & 3.1 & 6.9 & 10.2 & 9.6 \\
\hline & Max & 539.5 & 745.7 & $1,405.7$ & $1,458.6$ & $1,066.7$ & $1,113.5$ & 937.7 & 1610.0 & 1605.5 & 1623.6 \\
\hline
\end{tabular}


Table 2B. Summary Statistics for Selected Input Variables (As used in Analysis)

\begin{tabular}{|c|c|c|c|c|c|c|c|c|c|c|c|}
\hline Variable & & 1998 & 1999 & 2000 & 2001 & 2002 & 2003 & 2004 & 2005 & 2006 & 2007 \\
\hline \multicolumn{2}{|r|}{ Obs. } & 69 & 72 & 80 & 76 & 71 & 279 & 321 & 306 & 317 & 359 \\
\hline \multirow[t]{4}{*}{ Operating days } & Mean & 258.2 & 262.0 & 268.5 & 253.8 & 244.2 & 213.3 & 193.8 & 220.9 & 227.4 & 210.1 \\
\hline & $\mathrm{SD}$ & 32.6 & 41.1 & 41.1 & 45.2 & 44.0 & 54.7 & 51.7 & 56.2 & 57.0 & 53.6 \\
\hline & Min & 204.0 & 176.0 & 190.0 & 107.0 & 146.0 & 99.0 & 83.0 & 90.0 & 93.0 & 90.0 \\
\hline & $\operatorname{Max}$ & 338.0 & 364.0 & 348.0 & 338.0 & 342.0 & 354.0 & 342.0 & 345.0 & 355.0 & 338.0 \\
\hline \multirow{4}{*}{$\begin{array}{l}\text { Imputed days } \\
\text { at sea }\end{array}$} & Mean & 217.4 & 211.4 & 198.3 & 175.5 & 178.2 & 168.7 & 168.8 & 178.3 & 189.5 & 169.0 \\
\hline & $\mathrm{SD}$ & 33.2 & 40.0 & 50.1 & 42.8 & 46.6 & 46.9 & 46.0 & 58.7 & 56.2 & 53.9 \\
\hline & Min & 152.0 & 117.0 & 60.0 & 50.2 & 95.0 & 72.0 & 77.1 & 55.0 & 72.0 & 68.2 \\
\hline & Max & 295.0 & 322.0 & 343.0 & 335.0 & 287.0 & 336.0 & 324.6 & 330.0 & 345.0 & 325.0 \\
\hline \multirow{4}{*}{$\begin{array}{l}\text { Length times } \\
\text { Imputed days } \\
\text { at sea }\end{array}$} & Mean & 4169.2 & 4067.3 & 3748.1 & 3248.1 & 3197.8 & 2200.5 & 2237.6 & 2434.3 & 2605.8 & 2377.7 \\
\hline & $\mathrm{SD}$ & 1261.4 & 1449.2 & 1713.7 & 1312.7 & 1377.6 & 1090.4 & 1146.4 & 1349.6 & 1260.3 & 1247.1 \\
\hline & Min & 2133.6 & 1772.6 & 877.8 & 707.8 & 1459.2 & 696.0 & 672.0 & 581.9 & 816.4 & 606.6 \\
\hline & Max & 7707.8 & 8826.0 & 9415.4 & 9195.8 & 7720.7 & 8564.4 & 8898.0 & 9058.5 & 8771.2 & 8908.3 \\
\hline \multirow[t]{4}{*}{ Estimated effort } & Mean & 9.66 & 9.41 & 8.86 & 9.61 & 7.66 & 3.23 & 3.72 & 4.72 & 5.98 & 5.82 \\
\hline & $\mathrm{SD}$ & 6.01 & 6.71 & 7.21 & 6.77 & 5.74 & 2.95 & 3.32 & 4.31 & 5.23 & 5.43 \\
\hline & Min & 0.83 & 1.79 & 1.35 & 1.38 & 2.15 & 0.83 & 0.94 & 0.96 & 1.11 & 1.07 \\
\hline & Max & 29.18 & 36.55 & 36.11 & 35.33 & 31.54 & 25.54 & 25.03 & 28.99 & 39.45 & 41.24 \\
\hline
\end{tabular}


Table 3A. Rejection Rates - Operating days

\begin{tabular}{|c|c|c|c|c|}
\hline $\begin{array}{rr}\text { Years } \\
\end{array}$ & 3 & 6 & 8 & 10 \\
\hline Number of Vessels & 3 & & & 10 \\
\hline 5 & 0.01 & 0.00 & 0.04 & 0.22 \\
\hline 10 & 0.04 & 0.03 & 0.30 & 0.53 \\
\hline 50 & 0.40 & 0.58 & 0.96 & 1.00 \\
\hline 100 & 0.81 & 0.88 & 1.00 & 1.00 \\
\hline 150 & 0.93 & 1.00 & 1.00 & 1.00 \\
\hline
\end{tabular}

Table 3B. Rejection Rates - Imputed Days at Sea

\begin{tabular}{|c|c|c|c|c|}
\hline $\begin{array}{r}\text { Years } \\
\end{array}$ & 3 & 6 & 8 & 10 \\
\hline Number of Vessels & 3 & 0 & 0 & 10 \\
\hline 5 & 0.00 & 0.02 & 0.15 & 0.21 \\
\hline 10 & 0.01 & 0.02 & 0.28 & 0.55 \\
\hline 50 & 0.37 & 0.54 & 1.00 & 1.00 \\
\hline 100 & 0.65 & 0.90 & 1.00 & 1.00 \\
\hline 150 & 0.88 & 0.98 & 1.00 & 1.00 \\
\hline
\end{tabular}

Table 3C. Rejection Rates - Length Times Imputed Days at Sea

\begin{tabular}{|c|c|c|c|c|}
\hline $\begin{array}{r}\text { Years } \\
\end{array}$ & 3 & 6 & 8 & 10 \\
\hline Number of Vessels & & & & \\
\hline 5 & 0.01 & 0.00 & 0.07 & 0.18 \\
\hline 10 & 0.01 & 0.03 & 0.35 & 0.68 \\
\hline 50 & 0.29 & 0.62 & 1.00 & 1.00 \\
\hline 100 & 0.69 & 0.87 & 1.00 & 1.00 \\
\hline 150 & 0.95 & 0.99 & 1.00 & 1.00 \\
\hline
\end{tabular}

Table 3D. Rejection Rates - Estimated Total Effort

\begin{tabular}{|l|l|l|l|l|}
\hline \multicolumn{1}{|c|}{ Years } & 3 & 6 & 8 & 10 \\
\hline Number of Vessels & & 6 & & \\
\hline 5 & 0.01 & 0.00 & 0.09 & 0.19 \\
\hline 10 & 0.01 & 0.02 & 0.24 & 0.35 \\
\hline 50 & 0.22 & 0.49 & 0.98 & 1.00 \\
\hline 100 & 0.57 & 0.80 & 1.00 & 1.00 \\
\hline 150 & 0.77 & 0.95 & 1.00 & 1.00 \\
\hline
\end{tabular}


Table 4A. Rejection Rates - Operating Days, with Sampling Error

\begin{tabular}{|c|c|c|c|c|}
\hline $\begin{array}{r}\text { Years } \\
\end{array}$ & 3 & 6 & 8 & 1 \\
\hline Number of Vessels & 3 & 0 & 8 & 10 \\
\hline 5 & 0.00 & 0.15 & 0.26 & 0.21 \\
\hline 10 & 0.00 & 0.13 & 0.25 & 0.38 \\
\hline 50 & 0.03 & 0.15 & 0.31 & 0.59 \\
\hline 100 & 0.10 & 0.21 & 0.36 & 0.69 \\
\hline 150 & 0.18 & 0.28 & 0.40 & 0.75 \\
\hline
\end{tabular}

Table 4B. Rejection Rates - Imputed Days at Sea, with Sampling Error

\begin{tabular}{|c|c|c|c|c|}
\hline $\begin{aligned} \text { Years } \\
\end{aligned}$ & 3 & 6 & 8 & 10 \\
\hline Number of Vessels & & & 0 & \\
\hline 5 & 0.00 & 0.01 & 0.15 & 0.20 \\
\hline 10 & 0.00 & 0.00 & 0.25 & 0.51 \\
\hline 50 & 0.00 & 0.33 & 0.99 & 1.00 \\
\hline 100 & 0.00 & 0.70 & 1.00 & 1.00 \\
\hline 150 & 0.00 & 0.87 & 1.00 & 1.00 \\
\hline
\end{tabular}

Table 4C. Rejection Rates - Imputed Days at Sea Times Length, with Sampling Error

\begin{tabular}{|l|l|l|l|l|}
\hline \multicolumn{1}{|c|}{ Years } & 3 & 6 & 8 & 10 \\
\hline Number of Vessels & & 6 & & \\
\hline 5 & 0.01 & 0.00 & 0.07 & 0.18 \\
\hline 10 & 0.01 & 0.03 & 0.35 & 0.68 \\
\hline 50 & 0.29 & 0.62 & 1.00 & 1.00 \\
\hline 100 & 0.69 & 0.87 & 1.00 & 1.00 \\
\hline 150 & 0.95 & 0.99 & 1.00 & 1.00 \\
\hline
\end{tabular}

Table 4D. Rejection Rates - Estimated Effort, with Sampling Error

\begin{tabular}{|c|c|c|c|c|}
\hline Years & 3 & & & \\
\hline Number of Vessels & 3 & 6 & 8 & 10 \\
\hline 5 & 0.00 & 0.00 & 0.00 & 0.06 \\
\hline 10 & 0.00 & 0.00 & 0.00 & 0.14 \\
\hline 50 & 0.00 & 0.13 & 0.34 & 0.97 \\
\hline 100 & 0.00 & 0.40 & 0.73 & 1.00 \\
\hline 150 & 0.00 & 0.47 & 0.92 & 1.00 \\
\hline
\end{tabular}


Table 5 Distance to the Model, by Vessel Size and Property Rights Regime

\begin{tabular}{|c|c|c|c|c|c|c|c|}
\hline & & (1) & (2) & (3) & (4) & (5) & (6) \\
\hline $\begin{array}{l}\text { Measure } \\
\text { of Effort }\end{array}$ & & Combined & $\begin{array}{l}\text { Small } \\
\text { Before }\end{array}$ & $\begin{array}{l}\text { Small } \\
\text { After }\end{array}$ & $\begin{array}{l}\text { Large } \\
\text { Before }\end{array}$ & $\begin{array}{l}\text { Large } \\
\text { After }\end{array}$ & DD \\
\hline \multirow{2}{*}{$\begin{array}{l}\text { Operating } \\
\text { Days }\end{array}$} & $\begin{array}{l}\text { Adjusted } \\
\text { MSE }\end{array}$ & 1.44722 & 0.19987 & 1.30189 & 0.29854 & 3.82339 & 2.42 \\
\hline & KS p-val & 0.00 & 0.87 & 0.00 & 0.63 & 0.17 & -- \\
\hline \multirow{2}{*}{$\begin{array}{l}\text { Imputed } \\
\text { Days at } \\
\text { Sea }\end{array}$} & $\begin{array}{l}\text { Adjusted } \\
\text { MSE }\end{array}$ & 3.42457 & 0.04259 & 2.26897 & 2.23303 & 6.96962 & 2.51 \\
\hline & KS p-val & 0.00 & 0.99 & 0.00 & 0.72 & 0.42 & -- \\
\hline \multirow{2}{*}{$\begin{array}{l}\text { Days x } \\
\text { Length }\end{array}$} & $\begin{array}{l}\text { Adjusted } \\
\text { MSE }\end{array}$ & 0.028109 & 0 & 0.015547 & 0.019244 & 0.065333 & 0.03 \\
\hline & KS p-val & 0.00 & 1.00 & 0.00 & 0.72 & 0.35 & -- \\
\hline $\begin{array}{l}\text { Estimated } \\
\text { Total }\end{array}$ & $\begin{array}{l}\text { Adjusted } \\
\text { MSE }\end{array}$ & 498.53 & 105.41 & 361.38 & 430.94 & 905.80 & 218.9 \\
\hline Effort & KS p-val & 0.00 & 1.00 & 0.02 & 0.72 & 0.98 & -- \\
\hline
\end{tabular}

This table shows, for each of the four measures of effort, the mean-squared error (ie mean of the squared distances between model-consistent marginal costs and the revealed marginal costs), the mean-squared error adjusted for the number of constraints in the quadratic program (rather than the number of cells), and pvalue for the KS test. Results are shown separately for large and small vessels, for before and after the property rights reform, as well as for the combined model. 
Table 6A. Rejection Rates per Group with Weighted Sampling - Operating Days

\begin{tabular}{ccccccc}
\hline \hline Years & Vessels & \multicolumn{2}{l}{$\begin{array}{l}\text { Large- } \\
\text { after }\end{array}$} & \multicolumn{2}{l}{$\begin{array}{l}\text { Large- } \\
\text { before }\end{array}$} & \multicolumn{2}{l}{$\begin{array}{l}\text { Small- } \\
\text { after }\end{array}$} & $\begin{array}{l}\text { Small- } \\
\text { before }\end{array}$ & Diff-in-Diff \\
\hline 3 & 5 & 0.04 & 0.15 & 0.01 & 0.07 & -0.05 \\
3 & 10 & 0.28 & 0.30 & 0.08 & 0.23 & 0.13 \\
3 & 50 & 0.92 & 1.00 & 0.57 & 0.97 & 0.32 \\
\hline 4 & 5 & 0.19 & 0.16 & 0.05 & 0.08 & 0.06 \\
4 & 10 & 0.53 & 0.40 & 0.16 & 0.30 & 0.27 \\
4 & 50 & 1.00 & 0.99 & 0.89 & 1.00 & 0.12 \\
\hline 5 & 5 & 0.16 & 0.10 & 0.05 & 0.09 & 0.10 \\
5 & 10 & 0.48 & 0.46 & 0.18 & 0.29 & 0.13 \\
5 & 50 & 1.00 & 1.00 & 0.90 & 0.99 & 0.09 \\
\hline \hline
\end{tabular}

Table 6B. Rejection Rates per Group with Weighted Sampling - Imputed Days at Sea

\begin{tabular}{ccccccc}
\hline \hline Years & Vessels & $\begin{array}{l}\text { Large } \\
\text {-after }\end{array}$ & $\begin{array}{l}\text { Large } \\
\text {-before }\end{array}$ & $\begin{array}{l}\text { Small } \\
\text {-after }\end{array}$ & $\begin{array}{l}\text { Small } \\
\text {-before }\end{array}$ & Diff-in-Diff \\
\hline 3 & 5 & 0.13 & 0.07 & 0.04 & 0.09 & 0.11 \\
3 & 10 & 0.34 & 0.27 & 0.15 & 0.18 & 0.10 \\
3 & 50 & 1.00 & 1.00 & 0.80 & 1.00 & 0.20 \\
\hline 4 & 5 & 0.26 & 0.11 & 0.04 & 0.05 & 0.16 \\
4 & 10 & 0.48 & 0.28 & 0.24 & 0.21 & 0.17 \\
4 & 50 & 1.00 & 0.99 & 0.96 & 0.99 & 0.04 \\
\hline 5 & 5 & 0.23 & 0.14 & 0.11 & 0.07 & 0.05 \\
5 & 10 & 0.57 & 0.40 & 0.27 & 0.22 & 0.12 \\
5 & 50 & 1.00 & 1.00 & 0.99 & 0.99 & 0.00 \\
\hline \hline
\end{tabular}


Table 6C. Rejection Rates per Group with Weighted Sampling - Length times Days at Sea

\begin{tabular}{|c|c|c|c|c|c|c|}
\hline Years & Vessels & $\begin{array}{l}\text { Large- } \\
\text { after }\end{array}$ & $\begin{array}{l}\text { Large } \\
\text {-before }\end{array}$ & $\begin{array}{l}\text { Small } \\
\text {-after }\end{array}$ & $\begin{array}{l}\text { Small } \\
\text {-before }\end{array}$ & Diff-in-Diff \\
\hline 3 & 5 & 0.04 & 0.05 & 0.01 & 0.07 & 0.05 \\
\hline 3 & 10 & 0.36 & 0.23 & 0.09 & 0.24 & 0.28 \\
\hline 3 & 50 & 0.99 & 0.98 & 0.74 & 0.97 & 0.24 \\
\hline 4 & 5 & 0.04 & 0.09 & 0.07 & 0.11 & -0.01 \\
\hline 4 & 10 & 0.40 & 0.34 & 0.18 & 0.26 & 0.14 \\
\hline 4 & 50 & 1.00 & 1.00 & 0.82 & 0.99 & 0.17 \\
\hline 5 & 5 & 0.20 & 0.11 & 0.07 & 0.08 & 0.10 \\
\hline 5 & 10 & 0.60 & 0.33 & 0.19 & 0.18 & 0.26 \\
\hline 5 & 50 & 1.00 & 0.99 & 0.95 & 0.97 & 0.03 \\
\hline
\end{tabular}

Table 6D. Rejection Rates per Group with Weighted Sampling - Estimated Total Effort

\begin{tabular}{|c|c|c|c|c|c|c|}
\hline Years & Vessels & $\begin{array}{l}\text { Large } \\
\text {-after }\end{array}$ & $\begin{array}{l}\text { Large } \\
\text {-before }\end{array}$ & $\begin{array}{l}\begin{array}{l}\text { Small } \\
\text {-after }\end{array} \\
\end{array}$ & $\begin{array}{l}\begin{array}{l}\text { Small } \\
\text {-before }\end{array} \\
\end{array}$ & Diff-in-Diff \\
\hline 3 & 5 & 0.06 & 0.10 & 0.00 & 0.02 & -0.02 \\
\hline 3 & 10 & 0.21 & 0.17 & 0.03 & 0.08 & 0.09 \\
\hline 3 & 50 & 0.98 & 0.95 & 0.61 & 0.79 & 0.21 \\
\hline 4 & 5 & 0.09 & 0.12 & 0.04 & 0.05 & -0.02 \\
\hline 4 & 10 & 0.35 & 0.36 & 0.10 & 0.08 & -0.03 \\
\hline 4 & 50 & 1.00 & 0.99 & 0.76 & 0.75 & 0.00 \\
\hline 5 & 5 & 0.18 & 0.10 & 0.01 & 0.03 & 0.10 \\
\hline 5 & 10 & 0.47 & 0.30 & 0.12 & 0.10 & 0.15 \\
\hline 5 & 50 & 1.00 & 0.99 & 0.77 & 0.85 & 0.09 \\
\hline
\end{tabular}


Table 7. Difference-in-Differences Treatment Effects Per Unit Effort

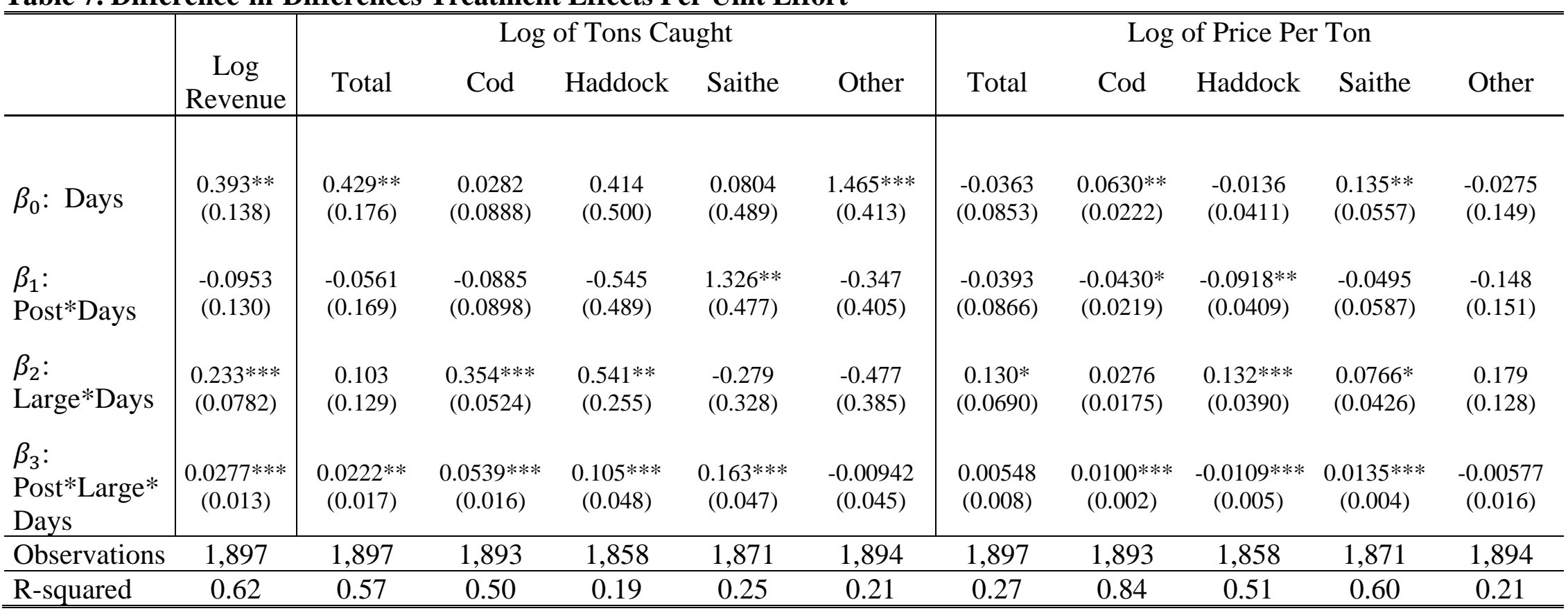

All regressions include year and vessel-size dummies. Standard errors, clustered by year and size category, in parentheses.

$* * * \mathrm{p}<0.01, * * \mathrm{p}<0.05, * \mathrm{p}<0.10$ 


\section{Appendix A. Proofs.}

the following statements on a panel data set $\mathcal{O}=\left\{p_{t} F_{t},\left(q_{i, t}\right)_{i \in 1 \ldots N}\right\}_{t \in 1 \ldots T}$ are equivalent:

(A) The set $\mathcal{O}$ is consistent with the tragedy of the commons with concave production function and convex cost function.

(B) There exists a set of nonnegative numbers $\left\{C_{i, t}^{\prime}\right\}_{i \in 1 \ldots N}$ that satisfy the linear program:

(i) $\frac{p_{t} \mathrm{~F}_{t}\left(Q_{t}\right)-Q_{t} c_{i, t}^{\prime}}{q_{i, t}}=\frac{p_{t} \mathrm{~F}_{t}\left(Q_{t}\right)-Q_{t} C_{j, t}^{\prime}}{q_{j, t}} \geq 0 \forall i, j \in I, \forall t \in T$;

(ii) $\left(q_{i, t}-q_{i, t^{\prime}}\right)\left(C_{i, t}^{\prime}-C_{i, t^{\prime}}^{\prime}\right) \geq 0 \forall i \in I, \forall t, t^{\prime} \in T$;

(iii) $C_{i, t}^{\prime} \geq 0 \forall i \in I, \forall t \in T$.

\section{$\underline{\text { Proof }}$}

Our proof is straightforward and follows the outline of Carvajal et al. (2013). To see (A) implies (B), suppose that the data are rationalized with production $\left\{p_{t} F_{t}, q_{i, t}\right\}_{i \in 1 \ldots N, t \in 1 \ldots T}$. Then the first order condition guarantees the existence of $\left\{C_{i, t}^{\prime}\right\}_{i \in 1 \ldots N}$ that satisfy the common ratio property (i). Given convexity of costs, the co-monotone property (ii) is satisfied as well.

To see (B) implies (A), we first show that at observation $t$, when (i) is satisfied, there exists a concave production function $F_{t}$ such that $\bar{F}_{t}\left(Q_{t}\right)=F_{t}$, and with each firm having the cost function $\bar{C}_{i},\left\{q_{i, t}\right\}_{i \in 1 \ldots N, t \in 1 \ldots T}$, which constitutes behavior consistent with the tragedy-of-the-commons model. We define $\bar{F}_{t}\left(Q_{t}\right)$ by $p_{t} \bar{F}_{t}^{\prime}\left(Q_{t}\right)=\frac{p_{t} \bar{F}_{t}\left(Q_{t}\right)}{Q_{t}}-b_{t}$ and let $b_{t}=\frac{p_{t} \mathrm{~F}_{t}\left(Q_{t}\right)-Q_{t} C_{i, t}^{\prime}}{q_{i, t}}$. A concave function will satisfy the definition here since the average return is larger than the marginal return. Firm $i$ 's decision is to choose $q_{i, t}$ that maximizes profit $\left\{\frac{q_{i, t}}{Q_{t}} * p_{t} F_{t}\left(Q_{t}\right)\right\}-C_{i, t}^{\prime}$; this function is concave, so the input level is optimal if and only if it obeys the first-order condition. Apply $\bar{F}_{t}\left(Q_{t}\right)$ defined above, we have $\frac{q_{i, t}}{Q_{t}} * p_{t} \bar{F}_{t}^{\prime}\left(Q_{t}\right)+\left(1-\frac{q_{i, t}}{Q_{t}}\right) * \frac{p_{t} \bar{F}_{t}\left(Q_{t}\right)}{Q_{t}}-C_{i, t}^{\prime}=\frac{q_{i, t}}{Q_{t}}\left(\frac{p_{t} \bar{F}_{t}\left(Q_{t}\right)}{Q_{t}}-\frac{p_{t} \bar{F}_{t}\left(Q_{t}\right)-Q_{t} C_{i, t}^{\prime}}{q_{i, t}}\right)+$ $\left(1-\frac{q_{i, t}}{Q_{t}}\right) * \frac{p_{t} \bar{F}_{t}\left(Q_{t}\right)}{Q_{t}}-C_{i, t}^{\prime}=0$. Hence, $q_{i, t}$ is the profit-maximizing input of firm $i$ at time $t$.

Second, we show that if for some firm $i$ there are positive scalars $\left\{C_{i, t}^{\prime}\right\}_{T \in 1 \ldots T}$ that are increasing with $q_{i, t}$, then there exists a convex cost function $\bar{C}_{i}$ such that $C_{i, t}^{\prime} \in \bar{C}_{i}\left(q_{i, t}\right)$. Proof of this part is the same as in Lemma 2 in Carvajal et al. (2013). 
Using the two conclusions above, we see that constraint (i) confirms that the choice of input $q_{i, t}$ is the optimal choice that satisfies the first order condition of the TOC model. And constraints (i) and (ii) ensure that marginal costs revealed from the linear program is the taken from a time-invariant convex cost function. Constraint (iii) ensures the nonnegativity of marginal costs. Hence, satisfying the three properties in the linear program implies consistency with the TOC model. 


\section{Appendix B. Simulations}

As described in Section 3.4, we generated data from four simulations, under TOC and IFQ property rights regimes, each with low and high cost parameters. In particular, we assume that aggregate output is generated from a Cobb-Douglas production function, with inputs of total fishing effort $(Q)$ and the stock of fish $(X)$ and equal weights. We also normalize the price of fish to one in every period: $p_{t} F_{t}\left(Q_{t}\right)=X_{t}^{0.5} Q_{t}^{0.5}$.

There are 100 firms, which each take the price of fish $(p)$ as exogenous. Costs are quadratic in effort, $C_{i}\left(q_{i}\right)=\frac{1}{2} c_{i} q_{i}^{2}$. Thus, marginal costs are linear $C_{i}^{\prime}\left(q_{i}\right)=c_{i} q_{i}$. Substituting these functions into Equation (2) and multiplying both sides by $Q / q_{i}$, the first-order conditions for firm $i$ is: $\left(\frac{1}{q_{i}}-\frac{1}{Q}\right) Q^{0.5} X^{0.5}+\frac{1}{2} Q^{-0.5} X^{0.5}-c_{i} Q=0$.

In the low-cost scenario, we set the cost parameter for the first firm $c_{1}=3$ and introduce heterogeneity by sequentially increasing each firm's cost parameter by 0.5 , i.e. $c_{i+1}-c_{i}=0.5$. For the highcost scenario, we set $c_{1}=5$ increase costs at a rate of 0.8 . In the open access regime, the low-cost scenario more dramatically depletes the resource base over time, so induces more variation in behavior.

Following the standard Gordon-Schaefer bioeconomic model, we assume fish stocks $X$ grow logistically:

$$
X_{t+1}-X_{t}=r X_{t}\left(1-\frac{X_{t}}{K}\right)-F_{t}
$$

for growth rate $r$ and carrying capacity $K$. We set $r=0.7$ and $K=100$. We initialize the stock of fish at $80 \%$ of its carrying capacity (i.e. $X_{1}=80$ ) and simulate fifteen periods.

Table B1 shows the rejection rates for these models, based on repeated draws from subsamples of the data, as described in Section 2.2. We never reject the TOC model under simulated TOC conditions. We reject the TOC model under simulated IFQ conditions at least $20 \%$ of the time for samples with as little as 5 vessels and 3 years of data. Mechanically, these rates increase with larger subsamples, reaching $100 \%$ with 50 vessels included.

Table B2 summarizes the results from estimating "distance" to the TOC model using the full simulated data set, as described in Section 3.2. It displays summary statistics for the $\delta_{i, t}$ terms 
from that model. In the low-cost scenario with the TOC regime, all distances are zero, as no adjustments are required to fit the TOC model. In the high-cost scenario, very small adjustments are needed, presumably for numerical reasons. In the simulated IFQ regimes, the distances are much larger. For example, the mean absolute value of $\delta_{i, t}$ as a percent of marginal costs is about $2 \%$ in the high-cost scenario and $4 \%$ in the low-cost scenario, with outliers above $200 \%$ in both cases. 
Table B1. Rejection Rates of TOC Model for Simulated TOC and IFQ Regimes under Two Cost Scenarios

\begin{tabular}{cccccc}
\hline \hline \multirow{2}{*}{ Years } & \multirow{2}{*}{ Vessels } & \multicolumn{2}{c}{ Low Costs } & \multicolumn{2}{c}{ High Costs } \\
& & TOC Regime & IFQ Regime & TOC Regime & IFQ Regime \\
\hline 3 & 5 & 0 & 20 & 0 & 26 \\
3 & 10 & 0 & 52 & 0 & 52 \\
3 & 50 & 0 & 100 & 0 & 100 \\
3 & 100 & 0 & 100 & 0 & 100 \\
\hline 6 & 5 & 0 & 51 & 0 & 58 \\
6 & 10 & 0 & 77 & 0 & 82 \\
6 & 50 & 0 & 100 & 0 & 100 \\
6 & 100 & 0 & 100 & 0 & 100 \\
\hline 8 & 5 & 0 & 52 & 0 & 55 \\
8 & 10 & 0 & 83 & 0 & 87 \\
8 & 50 & 0 & 100 & 0 & 100 \\
8 & 100 & 0 & 100 & 0 & 100 \\
\hline 10 & 5 & 0 & 61 & 0 & 55 \\
10 & 10 & 0 & 87 & 0 & 93 \\
10 & 50 & 0 & 100 & 0 & 100 \\
10 & 100 & 0 & 100 & 0 & 100 \\
\hline \hline
\end{tabular}

The first two columns together define a set of samples, based on the number of vessels and years of data included in each sample. Each cell in the final four columns show the percentage of subsamples in which the TOC model is rejected. 
Table B2. Summary Statistics of Distance to the Model

\begin{tabular}{lcccc}
\hline \hline \multirow{2}{*}{ Summary Statistic } & \multicolumn{2}{c}{ Low Costs } & \multicolumn{2}{c}{ High Costs } \\
& TOC Regime & IFQ Regime & TOC Regime & IFQ Regime \\
\hline Root Mean Squared Error (RMSE) & 0 & 0.218 & 0.001 & 0.061 \\
RMSE as a Pct of Average MC & $0 \%$ & $7.11 \%$ & $0.04 \%$ & $2.12 \%$ \\
Pct of Observations with $\delta_{i, t} \neq 0$ & $0 \%$ & $76.73 \%$ & $5.13 \%$ & $39.07 \%$ \\
Mean of abs $\left(\delta_{i, t} / M C_{i, t}\right)$ & $0 \%$ & $4.35 \%$ & $<0.01 \%$ & $2.01 \%$ \\
Max of abs $\left(\delta_{i, t} / M C_{i, t}\right)$ & $0 \%$ & $253.26 \%$ & $1.02 \%$ & $219.89 \%$ \\
\hline \hline
\end{tabular}

This table shows summary statistics for the error term, $\delta_{i, t}$, from Section 3.2, under four simulated policy experiments. 


\section{Appendix C. Data and Additional Results}

Imputed days at sea

To impute days at sea when these observations are missing, we use the following regression model:

$$
\text { days at sea } a_{i, t}=\beta_{1} * \text { operation days } s_{i, t}+\beta_{2} * \text { fuel expenditur } e_{i, t}+\lambda_{t}+\varepsilon_{i, t} \text {, }
$$

where $\lambda_{t}$ denotes year fixed effects. Note we cannot include vessel fixed effects as they cannot be estimated for those vessels with insufficient data. We run the above model conditional on operation days $>0$ and days at sea $>0$, and use the predicted coefficients to estimate missing values of days at sea for observations with positive operating days. Table B1 gives the estimated regression coefficients from the above equation. Model 1 omits operation days; Model 2 includes it. Results from these models are displayed in Table C1. We use imputations from Model 2 in the main body of the paper.

Estimation of scalar-valued effort function.

We estimate an effort function of multiple inputs as discussed in Section 4.3, and shown in Equations (6) and (7). Table B2 displays our regression results. Column 1 introduces the individual inputs in levels, whereas Column 2 does so in logs (as shown in Equation (8)). We use Column 2 in our analysis, as it has a better fit.

Event Studies and Parallel trends

As part of our difference-in-differences analysis of Section 5.3, we considered event studies and tested for differences in pre-existing trends between large and small vessels. We fail to reject the hypothesis of parallel trends, for all outcomes. Figures C1 to C9 display the event study graphs, showing year-by-year differences in large vs small vessels, relative to 2003, along with 95\% confidence intervals based on standard errors clustered by fleet. They show persistent increases in quantity and price post-2003 for large vessels relative to small, especially for cod and saithe. 


\section{Table C1. Regression Model for Imputing Missing Days at Sea}

\begin{tabular}{|c|c|c|}
\hline Days at sea & Model 1 & Model 2* \\
\hline Operation days & $\begin{array}{c}0.875 * * * \\
(0.0223)\end{array}$ & $\begin{array}{l}0.808 * * * \\
(0.023)\end{array}$ \\
\hline Fuel expenditure & No & $\begin{array}{l}4.351 * * * \\
(0.646)\end{array}$ \\
\hline Year fixed effects & Yes & Yes \\
\hline $\mathrm{R}^{2}$ & 0.624 & 0.641 \\
\hline $\mathrm{N}$ & 964 & 964 \\
\hline
\end{tabular}

This table displays the results of regressing days at sea on other inputs, to impute days at sea for missing values. Standard errors in parentheses. ${ }^{* * *} \mathrm{p}<0.01,{ }^{* *} \mathrm{p}<0.05,{ }^{*} \mathrm{p}<0.1$.

Table C2. Regression Model of Effort Function

\begin{tabular}{lrr}
\hline \hline Total catch quantity & Log-Level & Log-Log \\
\hline Person-years & $0.090^{* * *}$ & $0.156^{* *}$ \\
& $(0.02)$ & $(0.057)$ \\
Fuel expenditure & $0.039^{* *}$ & $0.133^{* *}$ \\
& $(0.016)$ & $(0.031)$ \\
Labor compensation & $0.032^{* *}$ & $0.703^{* *}$ \\
& $(0.003)$ & $(0.041)$ \\
Year fixed effects & Yes & Yes \\
Vessel fixed effects & Yes & Yes \\
\hline $\mathrm{R}^{2}$ & 0.27 & 0.41 \\
$\mathrm{~N}$ & 1092 & 1092 \\
\hline \hline
\end{tabular}

This table displays the results from jointly estimating Equations (6) and (7), as described in Section 4.3. Standard errors in parentheses. $* * * \mathrm{p}<0.01$; ** $p<0.05$; * $p<0.1$ 
Figure C1. Event Study, Total Revenue

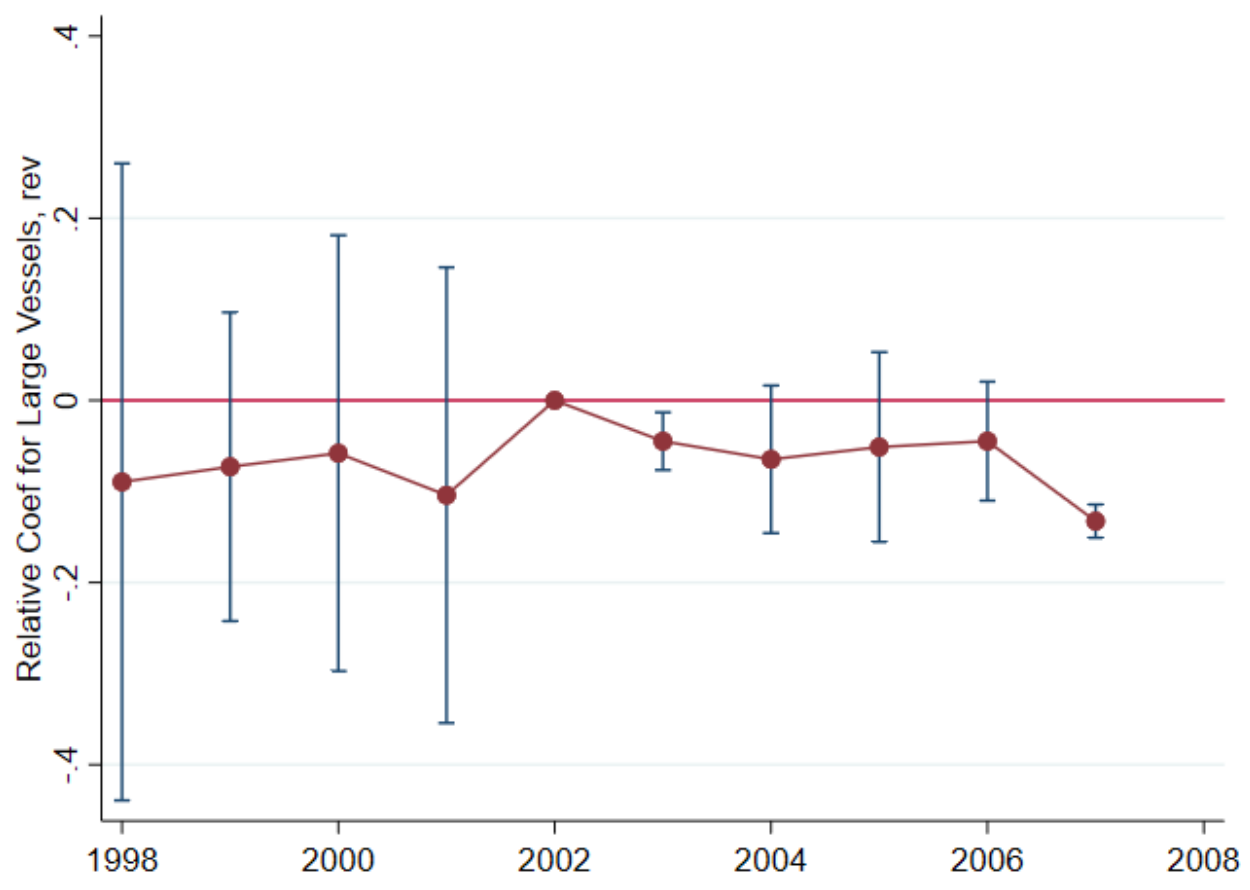

Figure C2. Event Study, Catch of Cod

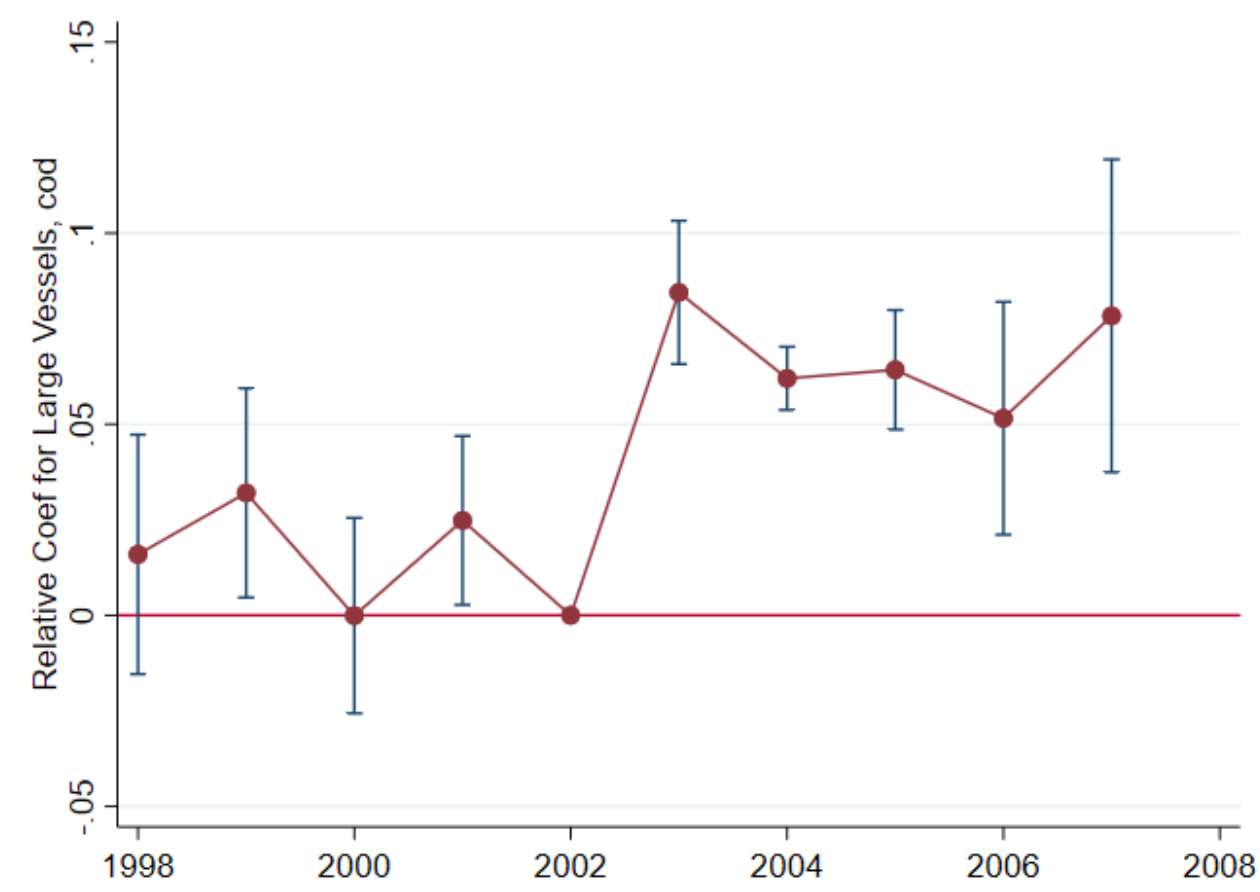


Figure C3. Event Study, Catch of Haddock

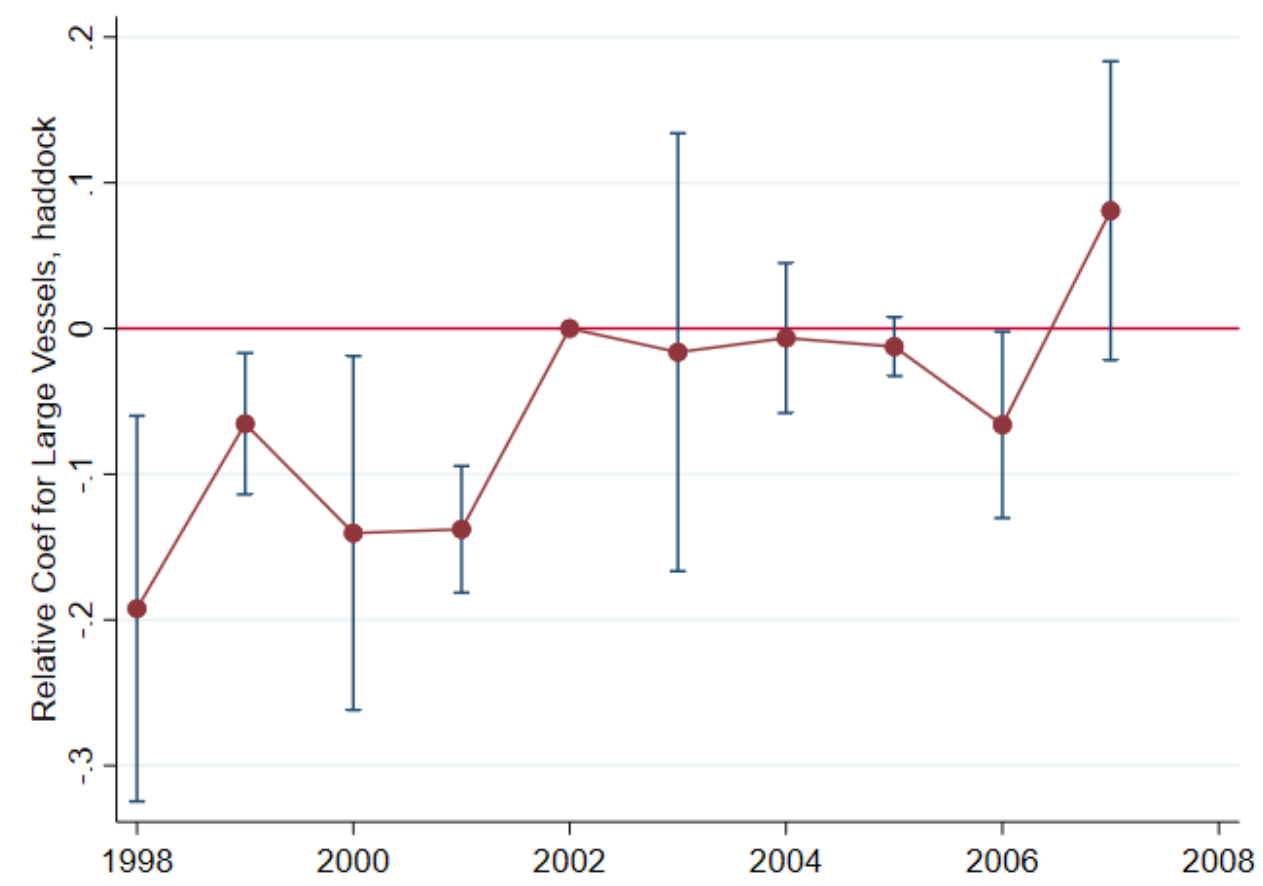

Figure C4. Event Study, Catch of Saithe

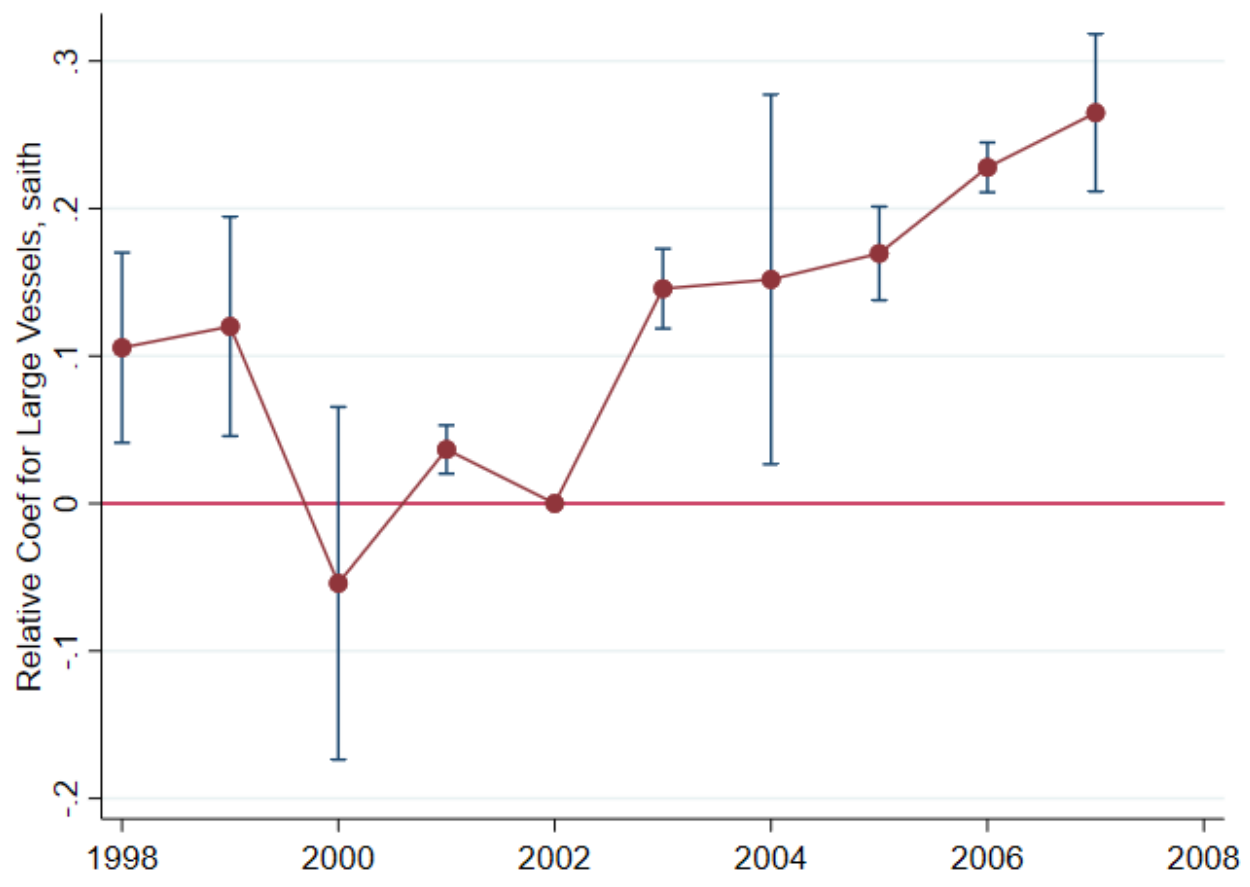


Figure C5. Event Study, Catch of Other Species

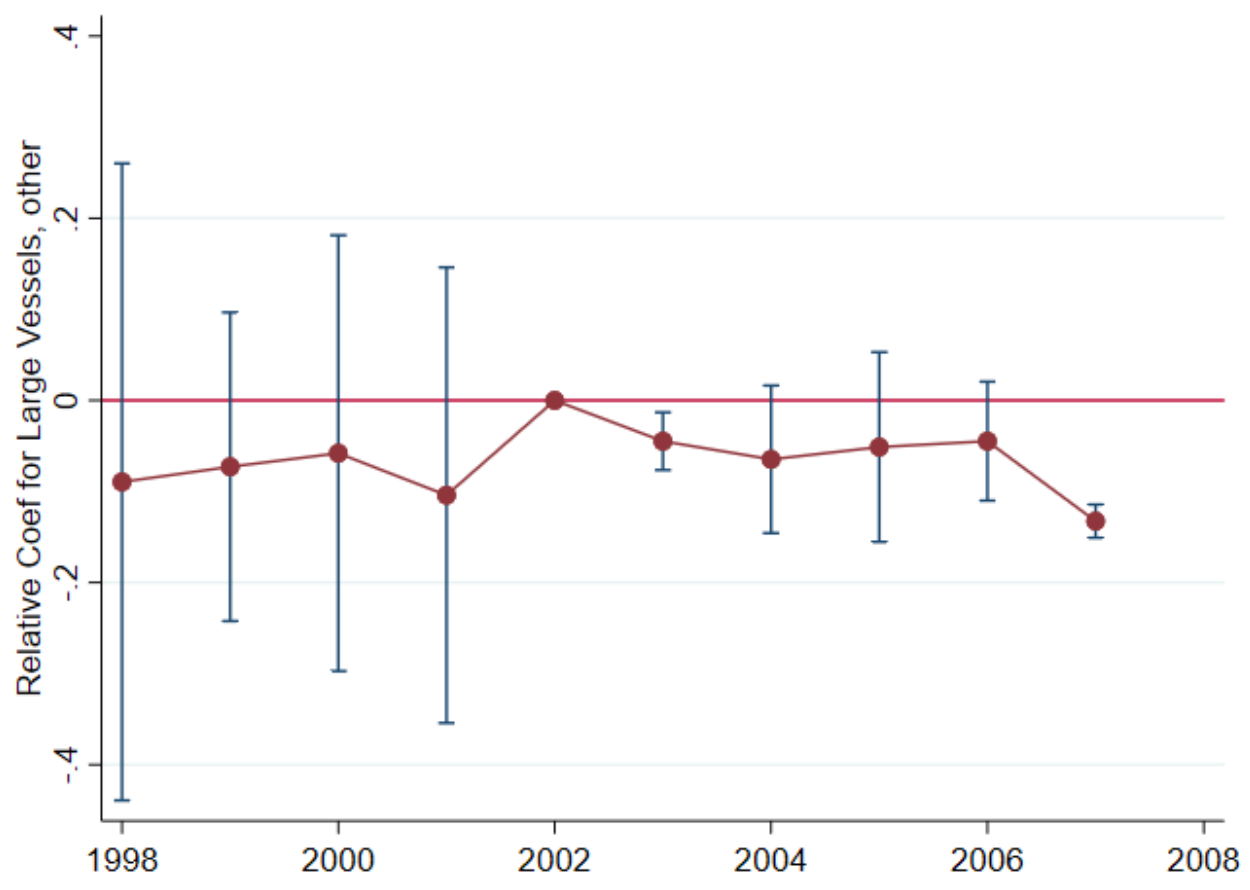

Figure C6. Event Study, Average Price of Cod

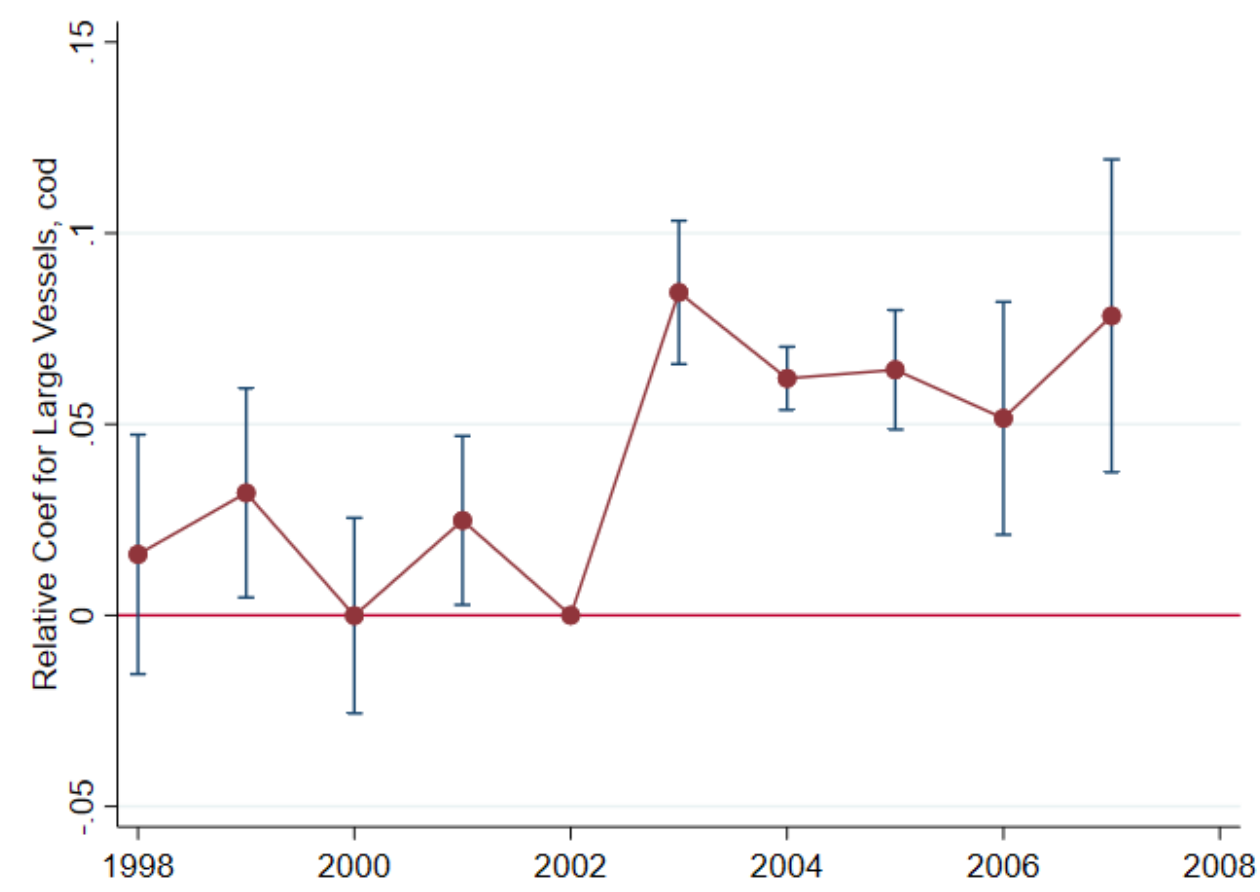


Figure C7. Event Study, Average Price of Haddock

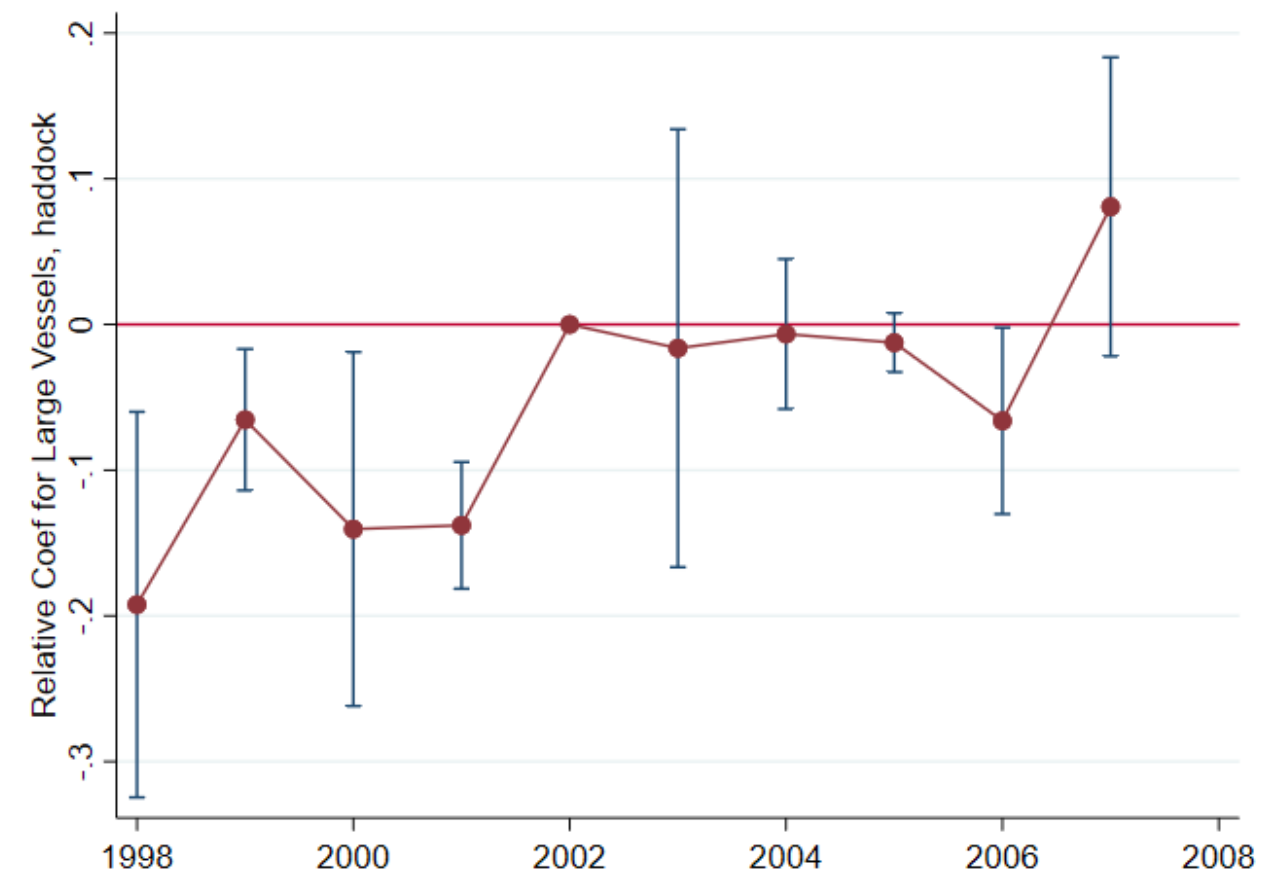

Figure C8. Event Study, Average Price of Saithe

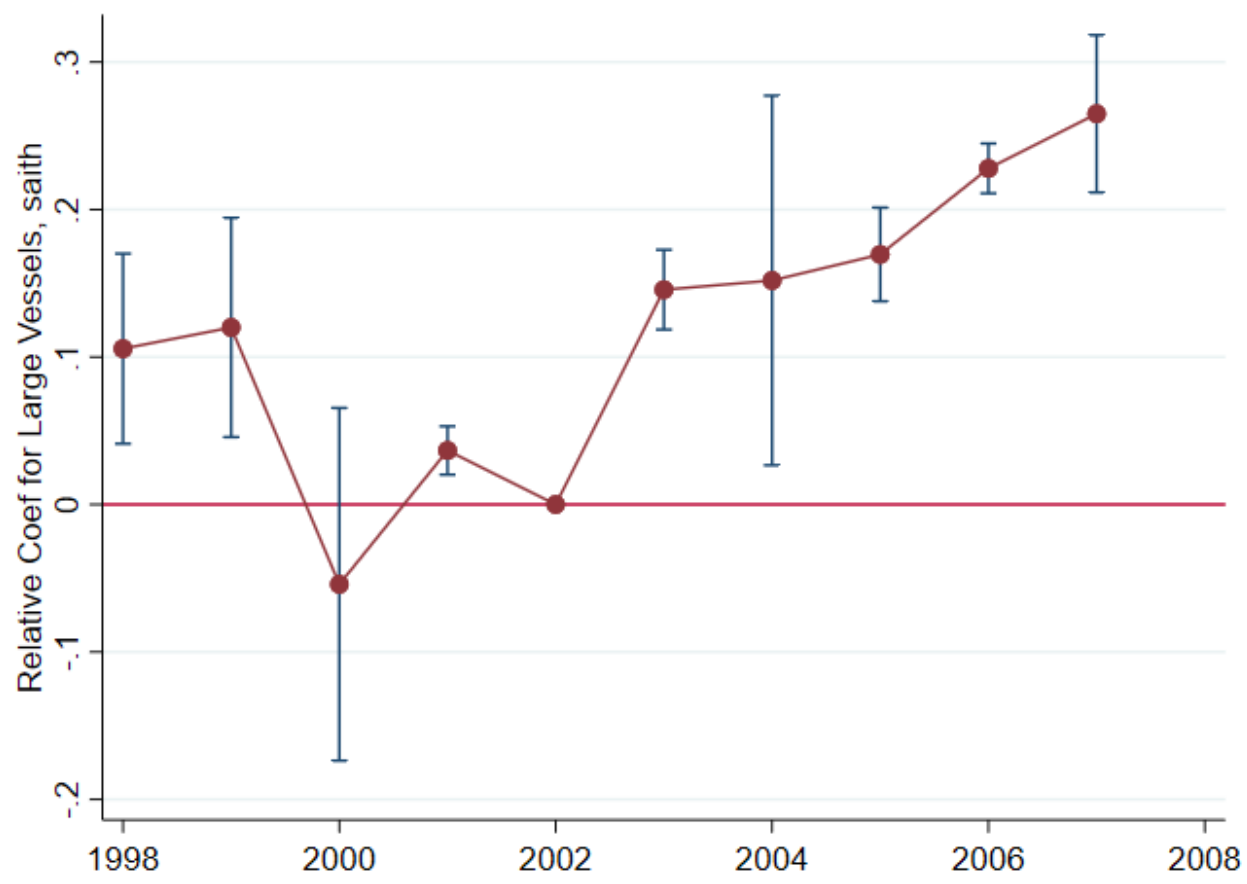


Figure C9. Event Study, Average Price of Other Species

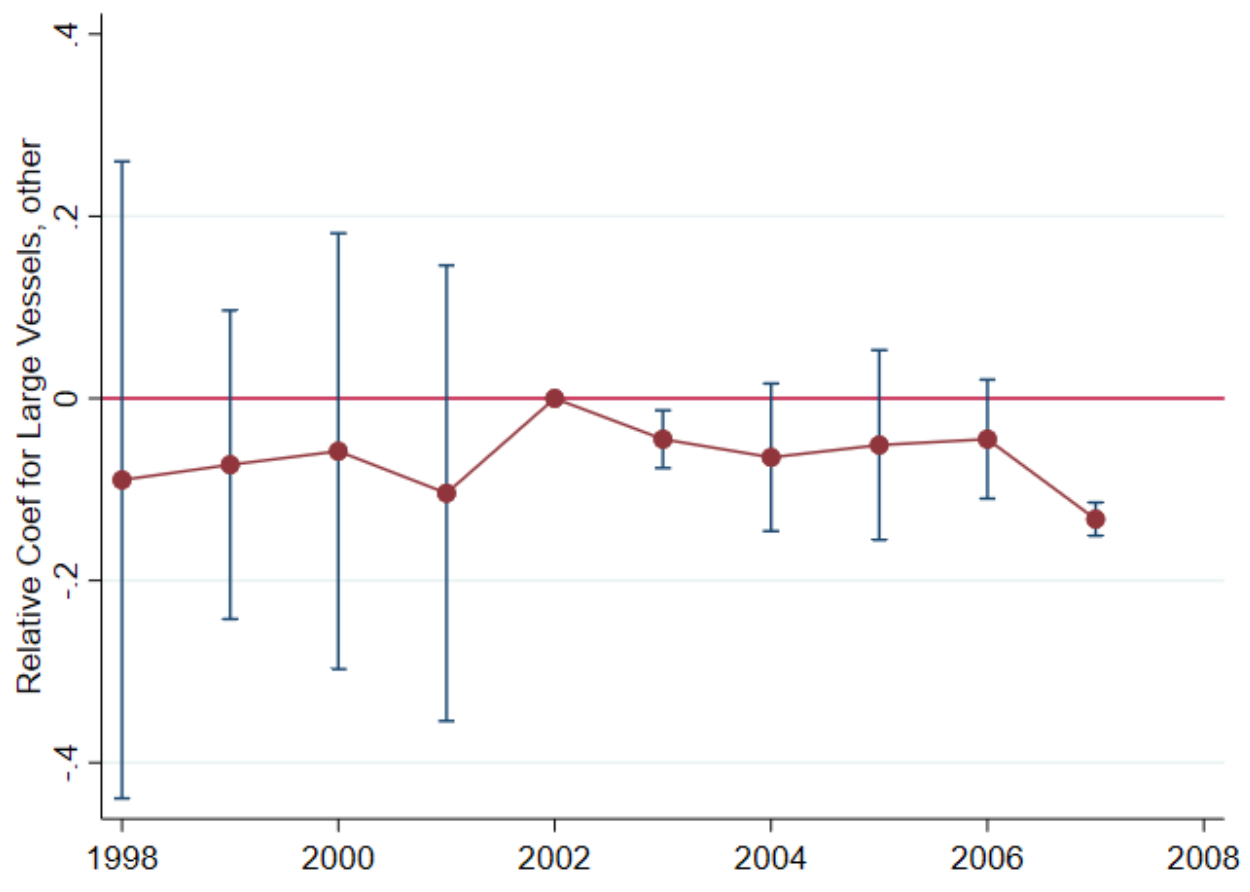

